Check for updates

Cite this: RSC Adv., 2019, 9, 12370

\title{
Synthesis of block cationic polyacrylamide precursors using an aqueous RAFT dispersion polymerization $\uparrow$
}

\author{
Bo Huang, ${ }^{a}$ Jie Jiang, ${ }^{a}$ Mutian Kang, ${ }^{a}$ Pingwei Liu, ${ }^{* a b}$ Hailong Sun, ${ }^{* c}$ Bo-Geng Li ${ }^{a}$ \\ and Wen-Jun Wang (DD *ab
}

Synthesis of cationic polyacrylamides (CPAMs) by introducing cationic polymer precursors followed by chain extension of acrylamide (AM) homopolymer blocks via RAFT polymerization is a promising approach for engineering high-performance CPAMs. However, the aqueous solution polymerization of AM usually leads to high viscosity, thus limiting the solid content in the polymerization system. Herein a novel approach is introduced that uses a random copolymer of AM and methacryloxyethyltrimethyl ammonium chloride (DMC) as a macro RAFT chain transfer agent (mCTA) and stabilizer for aqueous RAFT dispersion polymerization of AM. The AM/DMC random copolymers synthesized by RAFT solution polymerization, having narrow dispersities $\left(\biguplus_{s}\right)$ at different molecular weights and cationic degrees $\left(C_{s}\right)$, could serve as the mCTA, which was confirmed by mCTA chain extension in aqueous solution polymerization of $A M$ under different $C_{s}$, solid contents, $A M$ addition contents, extended PAM block lengths, and mCTA chain lengths. The block CPAMs had a $Đ$ value of less than 1.2. A model was developed using the method of moments with consideration of the diffusion control effect, for further understanding the chain extension kinetics. Predicted polymerization kinetics provided an accurate fit of the experimental data. The AM/DMC random copolymers were further used for aqueous RAFT dispersion polymerization of AM under different polymerization temperatures, $C_{s}$, and $\mathrm{mCTA}$ chain lengths. The resulting products had a milky appearance, and the block copolymers had $\Theta_{s}$ of less than 1.3. Higher $C_{s}$ and longer chain lengths on mCTAs were beneficial for stabilizing the polymerization systems and produced smaller particle sizes and less particle aggregation. The products remained stable at room temperature storage for more than a month. The results indicate that aqueous RAFT dispersion polymerization using random copolymers of AM and DMC at moderate cationic degrees as a stabilizer and $\mathrm{mCTA}$ is a suitable approach for synthesizing CPAM block precursors at an elevated solid content.

Received 11th April 2019

Accepted 11th April 2019

DOI: 10.1039/c9ra02716e

rsc.li/rsc-advances

\section{Introduction}

Water-soluble cationic polyacrylamides, CPAMs, have been widely used in mining, oil recovery, paper manufacturing, dust control, and sewage treatment. ${ }^{1}$ The cations in the CPAMs offer good electrostatic interaction properties with colloidal particles in water, which thus make them strong candidates for use as

${ }^{a}$ State Key Lab of Chemical Engineering, College of Chemical and Biological Engineering, Zhejiang University, 38 Zheda Road, Hangzhou 310027, China. E-mail: wenjunwang@zju.edu.cn; liupingwei@zju.edu.cn

${ }^{b}$ Institute of Zhejiang University - Quzhou, 78 Jiuhua Boulevard North, Quzhou, China 324000

'State Key Laboratory of Hydraulics and Mountain River Engineering, Sichuan University, 24 South Section 1, Yihuan Road, Chengdu, China 610064. E-mail: sunhl@scu.edu.cn

$\dagger$ Electronic supplementary information (ESI) available: ${ }^{1} \mathrm{H}$ NMR spectra of AM/DMC random copolymer (M1), and block CPAMs respectively synthesized by aqueous RAFT solution polymerization $\left(\mathrm{SA}_{281} \mathrm{C}_{70}-\mathrm{A}_{600}-3\right)$ and dispersion polymerization ( $\left.\mathrm{DA}_{170} \mathrm{C}_{177}-6-45\right)$. See DOI: $10.1039 / \mathrm{c} 9 \mathrm{ra} 02716 \mathrm{e}$ flocculation aids. ${ }^{1}$ Most commercial available CPAMs are random copolymers of acrylamide (AM) and cationic monomers, ${ }^{2}$ for instance, dimethyl diallyl ammonium chloride, acryloxyethyl trimethyl ammonium chloride, and methacryloxyethyltrimethyl ammonium chloride (DMC). In order to achieve good performance, CPAMs usually have very high molecular weights, ${ }^{3}$ which provide polymer chain bridging among colloidal particles to enhance flocculation efficiency in addition to the charge density. ${ }^{1}$ However, such a linear structure at high molecular weight restrains the number of the cations participating in electrostatic interaction with colloidal particles owing to random distribution of the cationic monomer, leading to inefficient use of cationic functionality, ${ }^{4-7}$ in addition to long dissolution time. Chain structure tuning makes it possible to improve the efficiency of utilizing cationic functionality in the CPAMs. It has been reported that flocculation performance can be enhanced via engineering a comb-branched CPAM possessing cationic homopolymer branches. ${ }^{4-7}$ Star structures ${ }^{8,9}$ have also been observed to promote flocculation. However, even with 
such structures, there is still a fraction of cationic monomers not performing. High charge density in polymerization of cationic monomer leads to difficulty in producing polymers of high molecular weight owing to the positive charge rejection. A copolymer of AM with a moderate cationic monomer content is believed to have the similar electrostatic interaction efficiency to that of a cationic homopolymer, which increases the efficiency of cationic monomer utilization. This can be accomplished through an arm-first strategy ${ }^{12-16}$ by positioning cationic copolymer blocks at branch ends of a hyperbranched AM homopolymer with CPAM precursors followed by chain extension of AM homopolymer block as arm. The resulting CPAMs have high flocculation efficiencies. ${ }^{17,18}$ However, such structures are not possible with conventional radical polymerization techniques, but can be produced using the Reversible AdditionFragmentation Chain Transfer (RAFT) Polymerization method..$^{10,11}$

A number of researchers have utilized RAFT polymerization in the generation of PAM. McCormick and co-workers ${ }^{19,20}$ investigated an aqueous RAFT polymerization of AM, while Schork et al. ${ }^{21}$ successfully synthesized PAM using an inverse mini-emulsion RAFT polymerization. AM could also be rendered to diblock or random hydrophilic/amphiphilic copolymers via RAFT copolymerization, such as block copolymers of AM with ionic liquid monomer ${ }^{22}$ or with monoacryloxyethyl phosphate, ${ }^{23}$ and random copolymers of AM with acrylonitrile. ${ }^{24}$ The RAFT copolymerization could synthesize multiblock copolymers likewise, such as a ABA triblock copolymer of AM and styrene as a supramolecular elastomer, ${ }^{25}$ or a triblock of AM, acrylonitrile, and $N, N$-diethylamino ethyl methacrylate as a stimuli responsive material. ${ }^{26}$ In a dispersed system, ${ }^{27}$ AM/sodium 2-acrylamido-2-methylpropanesulfonate random copolymer was synthesized via RAFT copolymerization. An imprinted AM copolymer was also synthesized using RAFT precipitation polymerization. ${ }^{28} \mathrm{Graft}$, star, or branch copolymers are also possible with RAFT polymerization. ${ }^{29-39}$ Shan et $a l .{ }^{40}$ used a multi-arm star RAFT chain transfer agent (CTA) to synthesize star PAM copolymers. A similar approach was used for preparation of hyperbranched copolymers with AM and acrylonitrile. ${ }^{41}$ Wang et al. ${ }^{14,15}$ synthesized hyperbranched PAMs using a semi-batch strategy by controlling crosslinker addition. The PAM-based nanogels were obtained via a RAFT dispersion polymerization. ${ }^{42}$

Although AM polymers can be synthesized by aqueous RAFT solution polymerization, high viscosities of polymerization systems at high solid contents limits control of the polymerization, and low solid content sacrifices polymerization efficiencies. This low-solid issue can be overcome with aqueous RAFT dispersion polymerization to produce CPAMs. ${ }^{43-45}$ During the dispersion polymerizations, stabilizers including watersoluble polymers, like poly(acryloyloxyethyl trimethylammonium chloride) ${ }^{44}$ and poly(ethylene glycol) ${ }^{45}$ are used to stabilize the polymerization system. We speculate that the copolymerization of cationic monomer with AM at moderate charge densities should provide similar stabilization as a homopolymer of the cationic monomer. In addition, if a RAFT functionality is introduced into the polymer chain, the copolymer could act as a macro RAFT chain transfer agent (mCTA) in addition to being a stabilizer. The macro RAFT chain transfer agent of cationic monomer with AM is believed to be facile for chain extension of AM, which is difficult to achieve when using the homopolymer of DMA having the terminal RAFT functionality. ${ }^{46}$ An approach of using cationic monomer as a stabilizer and macro RAFT chain transfer agent (as well as a component of final product) for aqueous RAFT dispersion copolymerization is thus developed for synthesizing block CPAMs at elevated solid contents. These block CPAMs are the precursors for further producing star or hyperbranched CPAMs with cationic blocks situated at polymer chain ends. ${ }^{47-50}$

Model-based polymer chain productions provide precise control over copolymer composition and chain topology distributions. ${ }^{51-53}$ Much attention has been paid to model developments for RAFT polymerization. Vana and co-workers ${ }^{54}$ simulated the polymerization rate and dispersity $(D)$ during RAFT polymerization using Monte Carlo simulations, while Tobita $^{55,56}$ and Luo et al. ${ }^{57}$ modeled the RAFT mini-emulsion polymerization. Kinetic methods based on elementary reactions in RAFT processes are also commonly used for modeling. Barner-Kowollik and co-workers ${ }^{58-60}$ employed the commercial PREDICI software package to model a RAFT process. Vivaldo Lima et al. ${ }^{61}$ also used PREDICI to simulate RAFT dispersion polymerizations. By introducing the method of moments, Zhu et al. ${ }^{62}$ modeled RAFT polymerization and studied the influence of reaction rate constants. Vivaldo Lima et al. ${ }^{63-66}$ compared different RAFT polymerization mechanisms and investigated the effect of the fragmentation rate constants. Zhu and coworkers ${ }^{52,67}$ developed a semi-batch RAFT polymerization model in both homogeneous and heterogeneous systems for regulating the copolymer microstructure. Wang and co-workers ${ }^{16,68}$ prepared a series of hyperbranched polyacrylamide and poly(methyl methacrylate) by using semi-batch RAFT polymerization, and developed a comprehensive understanding of the branching mechanisms. ${ }^{16,59}$

In this work, we synthesized random co-polymers of AM and DMC with moderate cationic contents via an aqueous RAFT solution polymerization. The resulting copolymers could serve as both stabilizers and macro RAFT chain transfer agents for aqueous dispersion polymerization of $\mathrm{AM}$ in the present of ammonium sulfate. The block CPAMs are the precursors for further preparation of star or hyperbranched CPAMs having terminal cationic blocks. The synergy of CPAM and salt is beneficial for road dust suppression. ${ }^{69}$ To develop a better understanding of the MCTA chain extension kinetics with AM, an aqueous RAFT solution polymerization of AM with mCTA was also conducted. A mathematic model was developed and used to predict and guide the synthesis of block CPAM precursors under different experimental conditions, including various extended PAM chain lengths, DMC composition and chain length in mCTAs, and AM addition content. Furthermore, the aqueous dispersion RAFT polymerizations of AM using the MCTA as stabilizer under different polymerization temperatures, charge densities (cationic degrees, $C_{\mathrm{s}}$ ), and chain lengths of mCTA were investigated. The block CPAMs were synthesized at elevated solid contents using aqueous RAFT dispersion 
polymerization with random copolymer of cationic monomer and $\mathrm{AM}$ at moderate charge density as both stabilizer and macro RAFT chain transfer agent.

\section{Experimental}

\section{Materials}

AM ( $\geq 98.5 \%$, Shanghai Lingfeng Chemical Reagent) was purified by recrystallization in acetone, and DMC (80\% solution in water, Sigma-Aldrich) was washed and precipitated in acetone as well. Initiator 2,2'-azobis[2-(2-imidazolin-2-yl) propane] dihydrochloride (Va-044, $\geq 98 \%$, J\&K Chemical) and ammonium sulfate (AS, $\geq 99 \%$, Sinopharm Chemical Reagent) were used as received. The RAFT chain transfer agent, 3-benzyltrithiocarbonyl propionic acid (BCPA), was synthesized following a procedure from the literature. ${ }^{70}$ Other materials were used as received.

\section{Synthesis of AM/DMC random copolymers}

The AM/DMC random copolymers mCTAs were synthesized in acetate acid/sodium acetate buffer solution at $\mathrm{pH}=5.0$ and $50{ }^{\circ} \mathrm{C}$. BCPA was used as CTA while Va-044 served as the initiator. We take Run M3 as an example. A $250 \mathrm{~mL}$ flask equipped with a mechanical stirring mixer was charged with $7.11 \mathrm{~g}$ AM (0.1 mol), $25.96 \mathrm{~g}$ 80\% DMC (0.1 mol), $0.151 \mathrm{~g}$ BCPA (0.556 $\mathrm{mmol}$ ), and $157.9 \mathrm{~g}$ buffer solution subsequently. After purging with $\mathrm{N}_{2}$ for $1 \mathrm{~h}, 0.090 \mathrm{~g}$ Va-044 $(0.278 \mathrm{mmol})$ was introduced to the flask. The polymerization was initiated and kept at $50{ }^{\circ} \mathrm{C}$ for $6 \mathrm{~h}$ under the $\mathrm{N}_{2}$ protection. In order to eliminate the residual Va-044, the resulting solutions were kept at $80{ }^{\circ} \mathrm{C}$ in sealed bottles for an additional $6 \mathrm{~h}$.

\section{Synthesis of block CPAMs via aqueous RAFT solution polymerization}

The aqueous RAFT solution polymerization of AM was conducted using AM/DMC random copolymers as mCTA. The block CPAMs were produced via chain extension. As an example consider the run designated $\mathrm{SA}_{170} \mathrm{C}_{177}-\mathrm{A}_{600}-3$. This is a RAFT solution copolymerization run using $\mathrm{M} 3\left(\mathrm{PAM}_{170}-r-\mathrm{PDMC}_{177}\right)$ as mCTA, $[\mathrm{AM}]_{0} /[\mathrm{mCTA}]_{0}=600 / 1$, and $3.0 \mathrm{wt} \% \mathrm{AM}$ content. A portion of the $0.1 \mathrm{mmol}$ mCTA M3 solution (32.44 g), $4.27 \mathrm{~g}$ AM (0.06 mol), and $105.3 \mathrm{~g}$ acetate/acid acetate buffer solution were added into a $250 \mathrm{~mL}$ flask. After purging with $\mathrm{N}_{2}$ for $1 \mathrm{~h}, 0.016 \mathrm{~g}$ Va-044 (0.05 mmol) was charged into the flask. The polymerization was carried out at $50{ }^{\circ} \mathrm{C}$ for $3 \mathrm{~h}$. Aliquots were taken during polymerization and terminated by adding trace hydroquinone solution.

\section{Synthesis of block CPAMs via aqueous RAFT dispersion polymerization}

Dispersion polymerizations of AM were carried out using AM/ DMC random copolymers as both stabilizer and mCTA in the present of ammonium sulfate AS. The addition of salt to the water could induce block CPAMs to form a polymer-rich phase and become a dispersion system due to the salting-out phenomenon. Consider $\mathrm{DA}_{170} \mathrm{C}_{177}-6-50$ as an example. $\mathrm{A}$
$250 \mathrm{~mL}$ flask equipped with a mechanical stirring mixer was charged with $31.14 \mathrm{~g}$ M3 solution, which contained $0.0934 \mathrm{mmol}$ mCTA, $3.98 \mathrm{~g}$ AM (0.056 mol), $18.57 \mathrm{~g} \mathrm{AS}$, and $12.64 \mathrm{~g}$ deionized water. The polymerization system was purged with $\mathrm{N}_{2}$ for $1 \mathrm{~h}$, adjusted to $\mathrm{pH}=5.5$, initiated with $0.0151 \mathrm{~g}$ Va$044(0.0467 \mathrm{mmol})$, and kept at $50{ }^{\circ} \mathrm{C}$ for $3 \mathrm{~h}$ under the $\mathrm{N}_{2}$ protection (Scheme 1).

\section{Characterization}

Overall conversions were determined by the brominating titration method, ${ }^{71,72}$ while DMC conversions of mCTAs were determined with ${ }^{1} \mathrm{H}$ NMR spectra acquired on a Bruker Advance 400 spectrometer with $\mathrm{D}_{2} \mathrm{O}$ as solvent. Molecular weights were measured with a Polymer Laboratory PL-GPC 50 gel permeation chromatograph (GPC) equipped with three columns (PL aquagel-OH 50, PL aquagel-OH 40, and PL aquagel-OH 20) and a RI detector. The eluent was $0.4 \mathrm{~mol} \mathrm{~L}^{-1}$ sodium nitrate and $3 \mathrm{wt} \%$ acetonitrile/water solution at a flow rate of $0.8 \mathrm{~mL} \mathrm{~min}{ }^{-1}$ at $30^{\circ} \mathrm{C}$. The PEO standards $\left(M_{\mathrm{W} 1}=1190 \mathrm{~kg} \mathrm{~mol}^{-1}, D_{1}=1.21\right.$; $M_{\mathrm{W} 2}=885.5 \mathrm{~kg} \mathrm{~mol}^{-1}, \oplus_{2}=1.10 ; M_{\mathrm{W} 3}=77.35 \mathrm{~kg} \mathrm{~mol}^{-1}, \oplus_{3}=$ 1.05 , where $M_{\mathrm{W}}$ refers to weight-average molecular weight) were used for calibration. Particle sizes of CPAM dispersions were characterized by a dynamic light scattering analysis (DLS) using a Malvern Nanosizer ZS-90. Sample measurements were carried out at the polymerization temperatures. Samples were directly charged into polystyrene cuvettes and sonicated for $90 \mathrm{~s}$ to remove bubbles. Particle morphology in dispersions were characterized using a FEI Cryogenic Transmission Electron Microscope (Cryo-TEM, Talos F200c). Apparent viscosities of samples were measured with \#27 rotor at $5 \mathrm{rpm}$ and $25^{\circ} \mathrm{C}$ using a rotational viscometer (LVDV, Shanghai Fangrui Instrument Co., Ltd).

\section{Results \& discussion}

\section{Aqueous RAFT solution copolymerization of AM and DMC}

Six AM/DMC random copolymers were synthesized via aqueous RAFT solution polymerization. The experimental conditions and characterization results are summarized in Table 1 . It can be seen that all runs reached overall conversions of $>95 \%$ and dispersities within 1.2 (see Fig. 1). ${ }^{1} \mathrm{H}$ NMR spectrum of Run M1 is given in Fig. S1 of the ESI. $\dagger$ DMC was more reactive than AM. Number-average molecular weights $\left(M_{\mathrm{n}} \mathrm{s}\right)$ determined by GPC were close to those obtained from NMR measurements. Wellcontrolled AM/DMC random copolymer samples were produced.

Targeting the preparation of random copolymers having same chain length of $\left([\mathrm{AM}]_{0}+[\mathrm{DMC}]_{0}\right) /[\mathrm{BCPA}]_{0}=360$ and different cationic degrees, 4 runs having $\mathrm{C}$ of $20 \%$ (Run M1), 40\% (Run M2), 50\% (Run M3), and 60\% (Run M4) were synthesized. Their GPC traces in Fig. 1A are overlapping. They move to slightly higher molecular weight with the increasing cationic degree, indicating similar chain lengths for these copolymers. The copolymers having same cationic degree of $50 \%$ and different chain lengths were also prepared. Run M5 had a $M_{\mathrm{n}}$ of $28.8 \mathrm{~kg} \mathrm{~mol}^{-1}$, while $M_{\mathrm{n}} \mathrm{s}$ for Run M3 and M6 were 
<smiles>C=CC(N)=O</smiles>

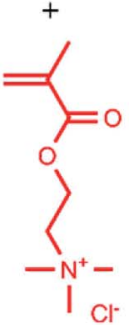

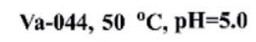

Water

RAFT Solution P'olymerization<smiles>C[SH](=S)=[SH]CCc1ccccc1CSCC(=O)O</smiles>

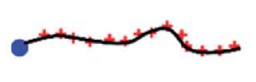

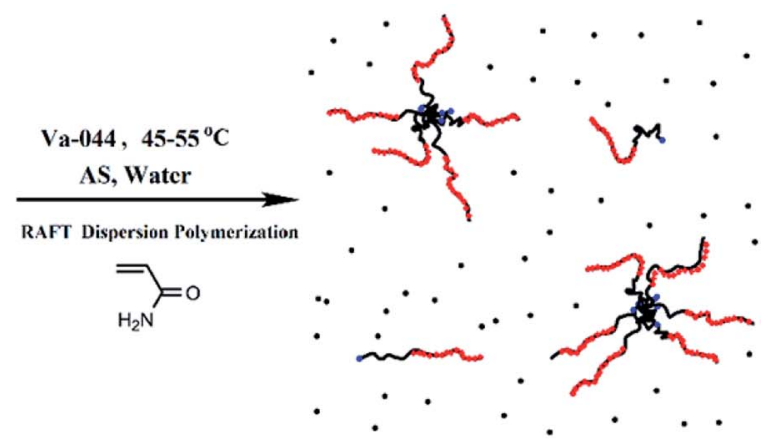

Aqueous CPAM Dispersion

Scheme 1 Synthesis of block CPAMs via aqueous RAFT dispersion polymerization.

48.8 and 69.2, respectively. The $\emptyset_{\mathrm{s}}$ for all three samples were within 1.2.

\section{Aqueous RAFT solution polymerization of AM using mCTA}

Ten RAFT solution polymerizations of AM using AM/DMC random copolymers as mCTA were carried out. The experimental conditions and characterization results are summarized in Table 2. ${ }^{1} \mathrm{H}$ NMR spectrum of Run $\mathrm{SA}_{281} \mathrm{C}_{70}-\mathrm{A}_{600}-3$ is shown in Fig. $\mathrm{S} 2$ of the ESI. $\dagger$ Run $\mathrm{SA}_{170} \mathrm{C}_{177}-\mathrm{A}_{600}-3$ was conducted using M3 as mCTA at $[\mathrm{AM}]_{0} /[\mathrm{M} 3]_{0} /[\mathrm{Va}-044]_{0}=1200 / 2 / 1$ and $\mathrm{C}=50 \%$. The $\mathrm{AM}$ conversion, $-\ln \left(1-X_{\mathrm{AM}}\right)$, and GPC trace versus polymerization time and $M_{\mathrm{w}}$ and $D$ versus conversion are given in Fig. 2. The narrow distributed GPC traces progress with polymerization time, indicating successful chain extension of AM/DMC random copolymer with AM. Linear relationships between $-\ln \left(1-X_{\mathrm{AM}}\right)$ and $t$ as well as $M_{\mathrm{w}}$ with $X_{\mathrm{AM}}$, and $Ð$ under 1.1 suggest a controlled characteristic in the polymerization using AM/DMC random copolymer as mCTA.

\section{Influence of mCTA cationic degree on kinetics and acquisition of model parameters}

Aqueous RAFT solution polymerizations of AM were conducted under mediation of mCTA having different cationic degrees ranging from 19.9 to $61.7 \%$. The conversions, molecular weights and distributions are plotted in Fig. 3. It can be seen that the mCTAs with approximately the same $M_{\mathrm{n}}$ but different cationic degrees had little influence on kinetics. The same kinetic parameters can be applied to the RAFT polymerization of AM using mCTAs with different charge densities.

A kinetic model was developed (see Appendix) for the aqueous RAFT solution polymerization of AM under mediation of mCTA. Most of the model parameters can be found from the literature as listed in Table 9 except $k_{\mathrm{a}}, k_{\mathrm{f}}$, and $k_{\mathrm{ct}}$, which were estimated from experimental data collected from Run $\mathrm{SA}_{281} \mathrm{C}_{70}-\mathrm{A}_{600}-3, \mathrm{SA}_{206} \mathrm{C}_{143}-\mathrm{A}_{600}-3, \mathrm{SA}_{170} \mathrm{C}_{177^{-}}-\mathrm{A}_{600}-3$, and $\mathrm{SA}_{133} \mathrm{C}_{214}-\mathrm{A}_{600}-3$.
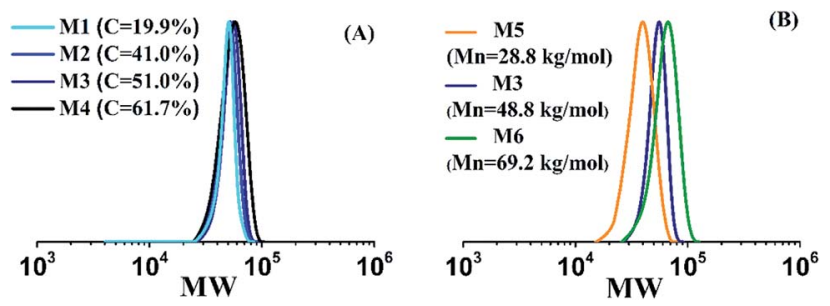

Fig. 1 GPC traces of AM/DMC random copolymer mCTAs having different cationic degrees (A) and chain lengths (B). Experimental conditions: $[\mathrm{BCPA}]_{0} /[\mathrm{Va}-044]_{0}=2 / 1$, solid content $(\mathrm{SC})=15.0 \mathrm{wt} \%$, $\mathrm{pH}=5.0$ (sodium acetate/acid acetate buffer solution), and $T=50^{\circ} \mathrm{C}$.

Table 1 Experimental conditions and results of synthesis of AM/DMC random copolymers ${ }^{a}$

\begin{tabular}{|c|c|c|c|c|c|c|c|c|c|}
\hline Run & {$[\mathrm{AM}]_{0} /[\mathrm{DMC}]_{0}{ }^{a}$} & $X^{b}(\%)$ & $x_{\mathrm{AM}}^{b}(\%)$ & $x_{\mathrm{DMC}}^{b}(\%)$ & Chain structure $^{c}$ & $C^{d}(\%)$ & $\mathrm{Mn}^{\mathrm{NMR}}\left(\mathrm{kg} \mathrm{mol}{ }^{-1}\right)$ & $\mathrm{Mn}^{\mathrm{GPC}, e}\left(\mathrm{~kg} \mathrm{~mol}^{-1}\right)$ & $\Xi^{e}$ \\
\hline M1 & $288 / 72$ & 97.4 & 97.6 & 96.6 & $\mathrm{PAM}_{281}-r-\mathrm{PDMC}_{70}$ & 19.9 & 34.4 & 41.1 & 1.1 \\
\hline M2 & $216 / 144$ & 96.8 & 95.4 & 99.0 & $\mathrm{PAM}_{206}-r-\mathrm{PDMC}_{143}$ & 41.0 & 43.6 & 45.7 & 1.2 \\
\hline M4 & $144 / 216$ & 96.4 & 92.3 & 99.1 & $\mathrm{PAM}_{133}-r-\mathrm{PDMC}_{214}$ & 61.7 & 53.9 & 52.6 & 1.2 \\
\hline M5 & $108 / 108$ & 95.4 & 94.5 & 96.3 & $\mathrm{PAM}_{102}-r-\mathrm{PDMC}_{104}$ & 50.5 & 28.8 & 34.1 & 1.2 \\
\hline M6 & $252 / 252$ & 97.9 & 96.7 & 99.1 & $\mathrm{PAM}_{244^{-}} r-\mathrm{PDMC}_{250}$ & 50.6 & 69.2 & 67.7 & 1.2 \\
\hline
\end{tabular}

${ }^{a}$ All runs had $[\mathrm{BCPA}]_{0} /[\mathrm{Va}-044]_{0}=2 / 1$, solid content $\mathrm{SC}=15.0 \mathrm{wt} \%, \mathrm{pH}=5.0$ (sodium acetate/acid acetate buffer solution), and $T=50{ }^{\circ} \mathrm{C}$. All $[\mathrm{AM}]_{0} /$ $[\mathrm{DMC}]_{\mathrm{o}}$ were based on $[\mathrm{BCPA}]_{0}=1 .{ }^{b}$ Overall conversion $(X)$, and AM $\left(x_{\mathrm{AM}}\right)$ and DMC conversions $\left(x_{\mathrm{DMC}}\right)$. Xs were determined using the brominate titration method, while $x_{\mathrm{DMC}} \mathrm{S}$ were determined from ${ }^{1} \mathrm{H}$ NMR spectra, and $x_{\mathrm{AM}} \mathrm{S}$ were estimated from both $X \mathrm{~S}$ and $x_{\mathrm{DMC}} \mathrm{S}$ for the copolymerizations.

${ }^{c}$ Resulting polymer chain structures are based on the AM and DMC conversions. ${ }^{d}$ Cationic degree values were calculated from ${ }^{1} \mathrm{H}$ NMR spectra.

${ }^{e}$ Number-average molecular weights and dispersities were determined by GPC. 
Table 2 Experimental conditions and results of aqueous RAFT solution polymerization of AM using mCTAs ${ }^{a}$

\begin{tabular}{|c|c|c|c|c|c|c|c|c|}
\hline Run & mCTA & {$[\mathrm{AM}]_{\mathrm{o}} /[\mathrm{mCTA}]_{0}$} & {$[\mathrm{AM}]_{\mathrm{o}}(\mathrm{wt} \%)$} & $X_{\mathrm{AM}}^{b}(\%)$ & Chain structure $^{c}$ & $\mathrm{Mn}^{\text {The,d }}\left(\mathrm{kg} \mathrm{mol}^{-1}\right)$ & $\mathrm{Mn}^{\mathrm{GPC}, e}\left(\mathrm{~kg} \mathrm{~mol}^{-1}\right)$ & $\Xi^{e}$ \\
\hline $\mathrm{SA}_{170} \mathrm{C}_{177}-\mathrm{A}_{300}-3^{f}$ & M3 & $300 / 1$ & 3.0 & 55.1 & $\left(\mathrm{PAM}_{170}-r-\mathrm{PDMC}_{177}\right)-b-\mathrm{PAM}_{165}$ & 60.5 & 65.0 & 1.1 \\
\hline $\mathrm{SA}_{170} \mathrm{C}_{177^{-}}-\mathrm{A}_{600^{-}}-3$ & M3 & $600 / 1$ & 3.0 & 82.5 & $\left(\mathrm{PAM}_{170}-r-\mathrm{PDMC}_{177}\right)-b-\mathrm{PAM}_{495}$ & 83.9 & 86.7 & 1.1 \\
\hline $\mathrm{SA}_{281} \mathrm{C}_{70}-\mathrm{A}_{600}-3$ & M1 & $600 / 1$ & 3.0 & 83.8 & $\left(\mathrm{PAM}_{281}-r-\mathrm{PDMC}_{70}\right)-b-\mathrm{PAM}_{503}$ & 70.1 & 73.5 & 1.1 \\
\hline $\mathrm{SA}_{206} \mathrm{C}_{143}-\mathrm{A}_{600}-3$ & M2 & $600 / 1$ & 3.0 & 79.1 & $\left(\mathrm{PAM}_{206}-r-\mathrm{PDMC}_{143}\right)-b-\mathrm{PAM}_{475}$ & 77.3 & 73.1 & 1.1 \\
\hline $\mathrm{SA}_{133} \mathrm{C}_{214}-\mathrm{A}_{600}-3$ & M4 & $600 / 1$ & 3.0 & 80.9 & $\left(\mathrm{PAM}_{133}-r-\mathrm{PDMC}_{214}\right)-b-\mathrm{PAM}_{485}$ & 88.3 & 86.9 & 1.1 \\
\hline $\mathrm{SA}_{170} \mathrm{C}_{177}-\mathrm{A}_{600}-1.5$ & M3 & $600 / 1$ & 1.5 & 78.7 & $\left(\mathrm{PAM}_{170}-r-\mathrm{PDMC}_{177}\right)-b-\mathrm{PAM}_{472}$ & 82.3 & 89.7 & 1.1 \\
\hline $\mathrm{SA}_{170} \mathrm{C}_{177}-\mathrm{A}_{600}-4.5$ & M3 & $600 / 1$ & 4.5 & 91.3 & $\left(\mathrm{PAM}_{170}-r-\mathrm{PDMC}_{177}\right)-b-\mathrm{PAM}_{548}$ & 87.7 & 93.9 & 1.1 \\
\hline
\end{tabular}

${ }^{a}$ All runs had $[\mathrm{mCTA}]_{0} /[\mathrm{Va}-044]_{0}=2 / 1, \mathrm{pH}=5.0$ (sodium acetate/acid acetate buffer solution), $T=50{ }^{\circ} \mathrm{C}$, and $t=2 \mathrm{~h} .{ }^{b}$ AM conversions were determined by brominate titration method. ${ }^{c}$ Resulting polymer chain structures are based on the AM conversions and mCTA chain structures. ${ }^{d}$ Theoretical number-average molecular weights are estimated from number-average molecular weights of mCTAs calculated from ${ }^{1} \mathrm{H}$ NMR spectra and PAM block lengths estimated from AM conversions. ${ }^{e}$ Number-average molecular weights and dispersities were determined by GPC.

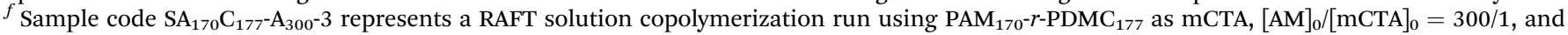
AM adding content of $3.0 \mathrm{wt} \%$.

\section{Effect of solid content on kinetics and diffusion-controlled termination correction}

The aqueous RAFT solution polymerizations of AM at different solid contents were conducted to investigate the diffusioncontrolled effect on the kinetics as shown in Fig. 4. Three AM addition contents were used including $1.5 \mathrm{wt} \%\left(\mathrm{SA}_{170} \mathrm{C}_{177^{-}}-\mathrm{A}_{600^{-}}\right.$ 1.5), $3.0 \mathrm{wt} \%\left(\mathrm{SA}_{170} \mathrm{C}_{177}-\mathrm{A}_{600}-3\right)$, and $4.5 \mathrm{wt} \%\left(\mathrm{SA}_{170} \mathrm{C}_{177}-\mathrm{A}_{600^{-}}\right.$ 4.5 ), corresponding to overall solid contents of $3.2,6.4$, and $9.6 \mathrm{wt} \%$, respectively. The conversions increased slightly at the same polymerization times when changing the AM addition contents from 1.5 to $3.0 \mathrm{wt} \%$, while the conversions went up substantially with the further increment of the AM addition contents from 3.0 to $4.5 \mathrm{wt} \%$, suggesting diffusion controlled reactions. RAFT polymerization of AM is quite rapid. Even at a low conversions, diffusion control occurs much earlier. This is a result of higher radical concentrations due to lower radical addition rates to CTA and reduced radical termination rates. ${ }^{75}$ However, this effect had little influence on the polymerization control. Run $\mathrm{SA}_{170} \mathrm{C}_{177}-\mathrm{A}_{600}-4.5$ samples still possessed narrow dispersities with linear increments of molecular weight versus polymerization times, which implies good control should be

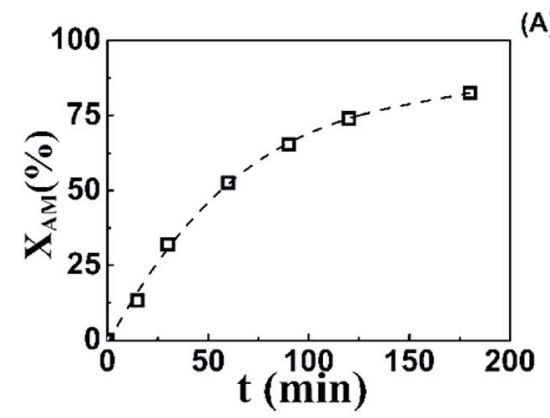

(A)

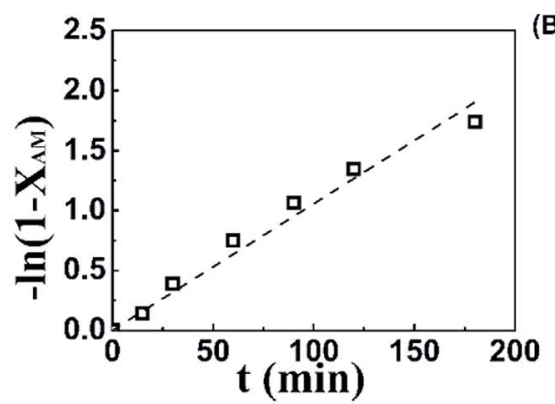

(B)

(C)
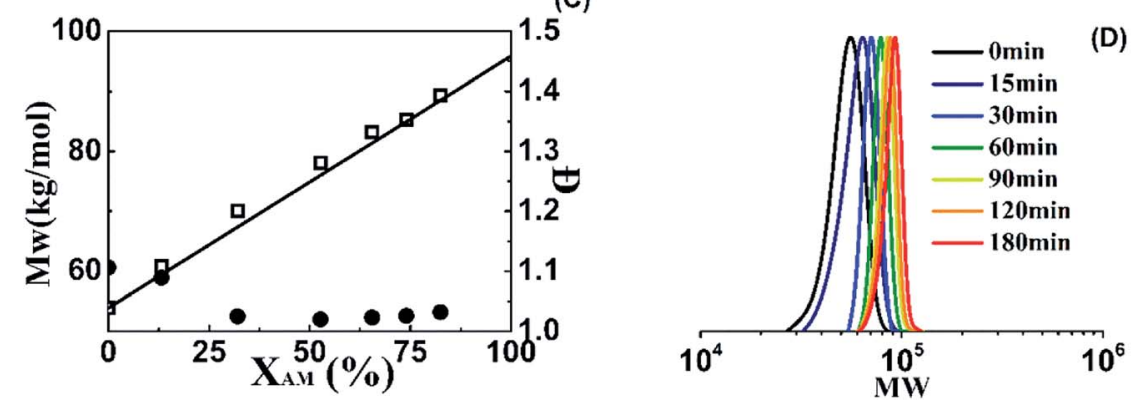

Fig. 2 Plots of characterizing the aqueous RAFT solution polymerization of AM using M3 as mCTA including (A) AM conversion versus polymerization time, $(B)-\ln \left(1-X_{A M}\right)$ versus polymerization time, $(C)$ weight-average molecular weight and dispersity versus $A M$ conversion, and (D) $\mathrm{GPC}$ trace of polymers at different polymerization times. Experimental conditions: $[\mathrm{AM}]_{0} /[\mathrm{M} 3]_{0} /[\mathrm{Va}-044]_{0}=1200 / 2 / 1,[\mathrm{AM}]_{0}=0.423 \mathrm{M}, \mathrm{pH}=$ 5.0, sodium acetate/acetate acid as buffer solution, and $t=50^{\circ} \mathrm{C}$. 

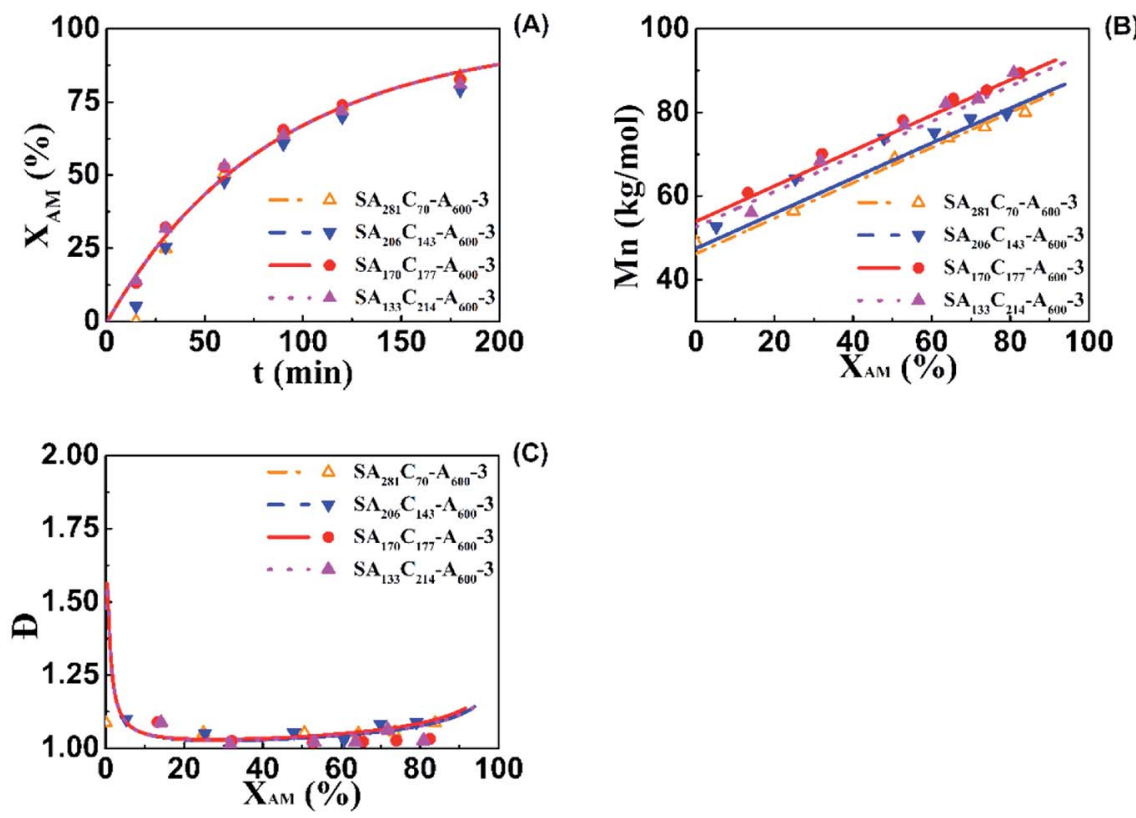

Fig. 3 Plots of characterizing the aqueous RAFT solution polymerization of AM with different mCTA cationic degrees including (A) AM conversion versus polymerization time, (B) number-average molecular weight versus AM conversion, and (C) dispersity versus AM conversion. Experimental conditions: $[\mathrm{AM}]_{0} /[\mathrm{mCTA}]_{0} /[\mathrm{Va}-044]_{0}=1200 / 2 / 1,[\mathrm{AM}]_{0}=0.423 \mathrm{M}, \mathrm{pH}=5.0$, sodium acetate/acetate acid as buffer solution, and $t$ $=50^{\circ} \mathrm{C}$. The points are experimental data while lines are model simulation results.

achievable in polymerization systems at high solid contents, such as aqueous dispersion systems.

To describe the diffusion-controlled effect, semi-empirical eqn (A5)-(A7) were used to quantify the termination constant with the consideration of contribution of number-average chain length $\left(\bar{r}_{\mathrm{N}}\right)$ and free volume fraction $\left(v_{\mathrm{f}}\right) .{ }^{77-79}$ When the solid content increases, the free volume fraction $v_{\mathrm{f}}$ decreases due to the existence of more polymer chains in the same volume. The
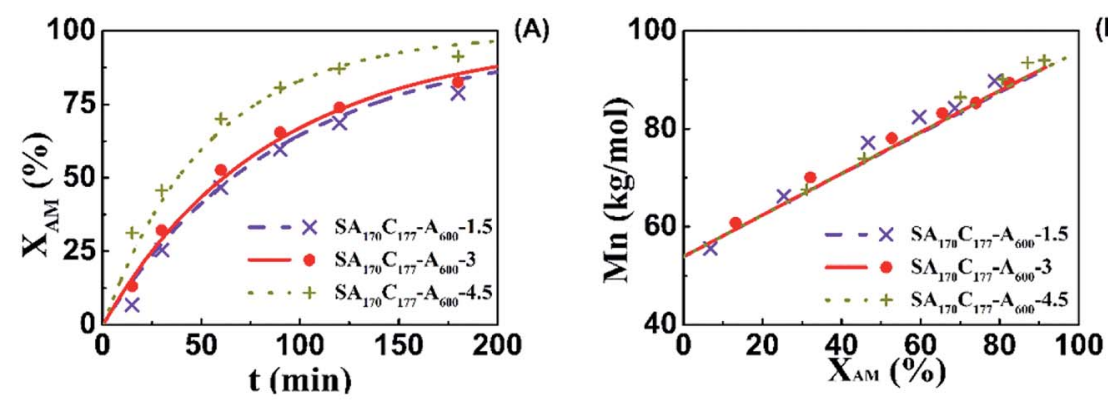

(B)
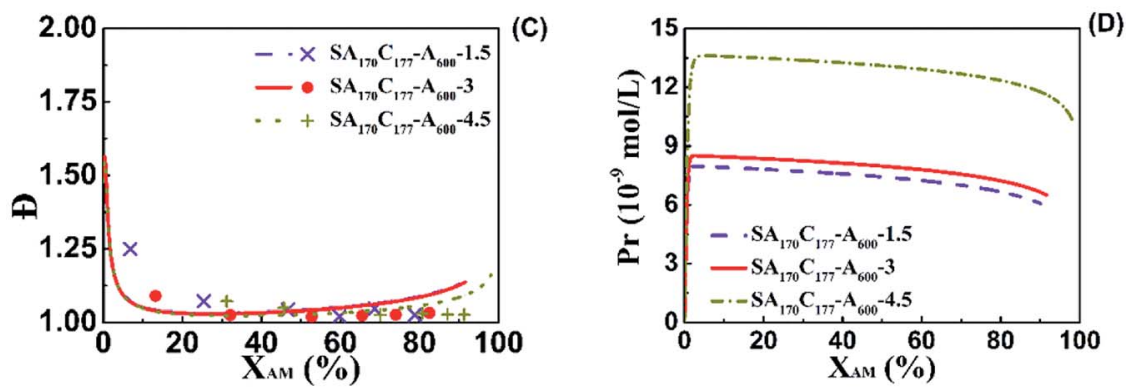

Fig. 4 Plots of characterizing the aqueous RAFT solution polymerization of AM with different AM addition contents including (A) AM conversion versus polymerization time, (B) number-average molecular weight versus AM conversion, (C) dispersity versus AM conversion, and (D) propagation radical $(\mathrm{Pr})$ concentrations estimated by the model. Experimental conditions: $[\mathrm{AM}]_{0} /[\mathrm{M} 3]_{0} /[\mathrm{Va}-044]_{0}=1200 / 2 / 1, \mathrm{pH}=5.0$, sodium acetate/acetate acid as buffer solution, and $t=50{ }^{\circ} \mathrm{C}$. The points are experimental data while lines are model simulation results. 

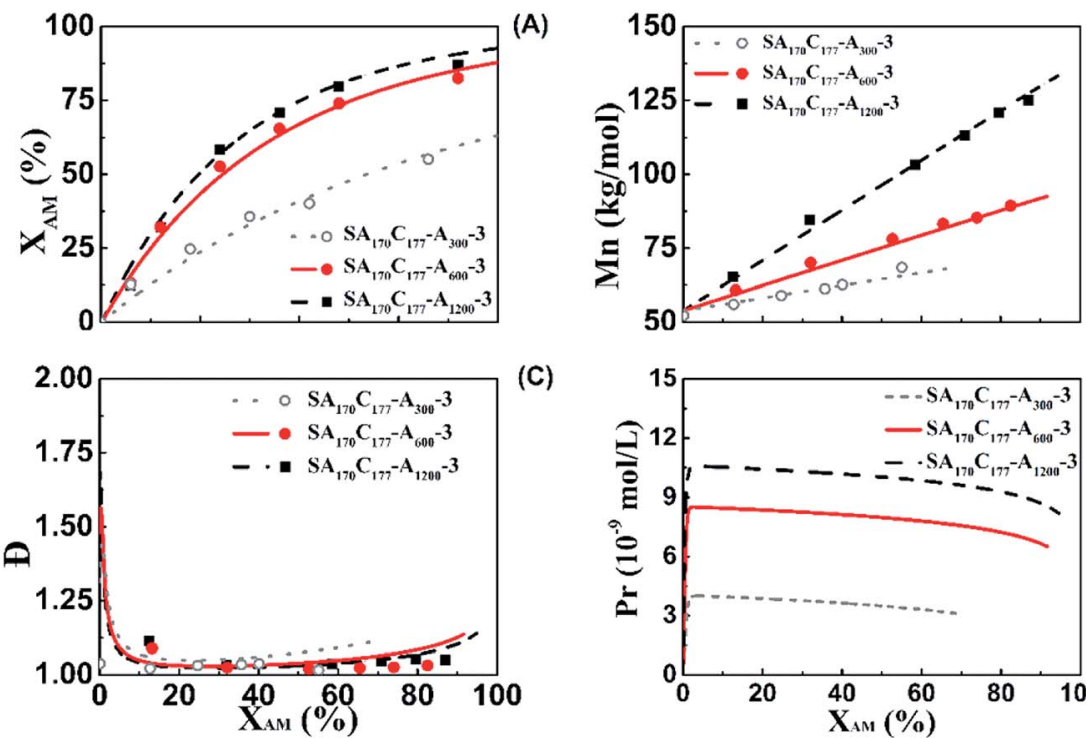

(C)

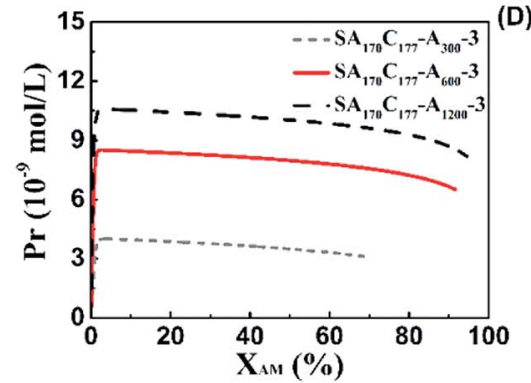

Fig. 5 Plots of summarizing model-predicted and experimental polymerization kinetics results for aqueous RAFT solution polymerization of AM at different extended PAM block lengths including (A) AM conversion versus polymerization time, (B) number-average molecular weight versus AM conversion, (C) dispersity versus AM conversion, and (D) propagation radical concentration (Pr) values estimated with the model. Experimental conditions: $[\mathrm{M} 3]_{0} /[\mathrm{Va}-044]_{0}=2 / 1,[\mathrm{M} 3]_{0}=0.653 \mathrm{mM}, \mathrm{pH}=5.0$, sodium acetate/acetate acid as buffer solution, and $t=50{ }^{\circ} \mathrm{C}$. The lines are model-predicted results while the points are experimental data.

parameters of $k_{\mathrm{t}, \mathrm{D}}^{0}, a$, and $b$ in eqn (A6) were estimated from the experimental data of Run $\mathrm{SA}_{170} \mathrm{C}_{177}-\mathrm{A}_{600}-1.5, \mathrm{SA}_{170} \mathrm{C}_{177}-\mathrm{A}_{600}-3$ and $\mathrm{SA}_{170} \mathrm{C}_{177}-\mathrm{A}_{600}-4.5$, and listed in Table 9.

Measured viscosities of CPAM samples at $30 \mathrm{~min}$ with solids contents ranging from 1.5 to $4.5 \mathrm{wt} \%$ were $5.0 \mathrm{mPa} \mathrm{s}(X=$ $\left.25.4 \%, \mathrm{SA}_{170} \mathrm{C}_{177^{-}} \mathrm{A}_{600}-1.5\right), 14.2 \mathrm{mPa} \mathrm{s}\left(X=32.1 \%, \mathrm{SA}_{170} \mathrm{C}_{177^{-}}\right.$ $\left.\mathrm{A}_{600}-3\right)$, and $54.7 \mathrm{mPa} \mathrm{s}\left(X=45.7 \%, \mathrm{SA}_{170} \mathrm{C}_{177}-\mathrm{A}_{600}-4.5\right)$.
Corresponding propagation radical concentration $(\mathrm{Pr})$ values estimated from the model were $7.76 \times 10^{-9}, 8.24 \times 10^{-9}$, and $13.2 \times 10^{-9} \mathrm{~mol} \mathrm{~L}^{-1}$, respectively, as shown in Fig. 4D. Even for conversions as low as $32 \%$, the viscosity and Pr values were 5.8, 14.2 and $24.6 \mathrm{mPa}$ s and $7.69 \times 10^{-9}, 8.24 \times 10^{-9}$ and $13.4 \times$ $10^{-9} \mathrm{~mol} \mathrm{~L}^{-1}$, respectively. This indicates that the increase in
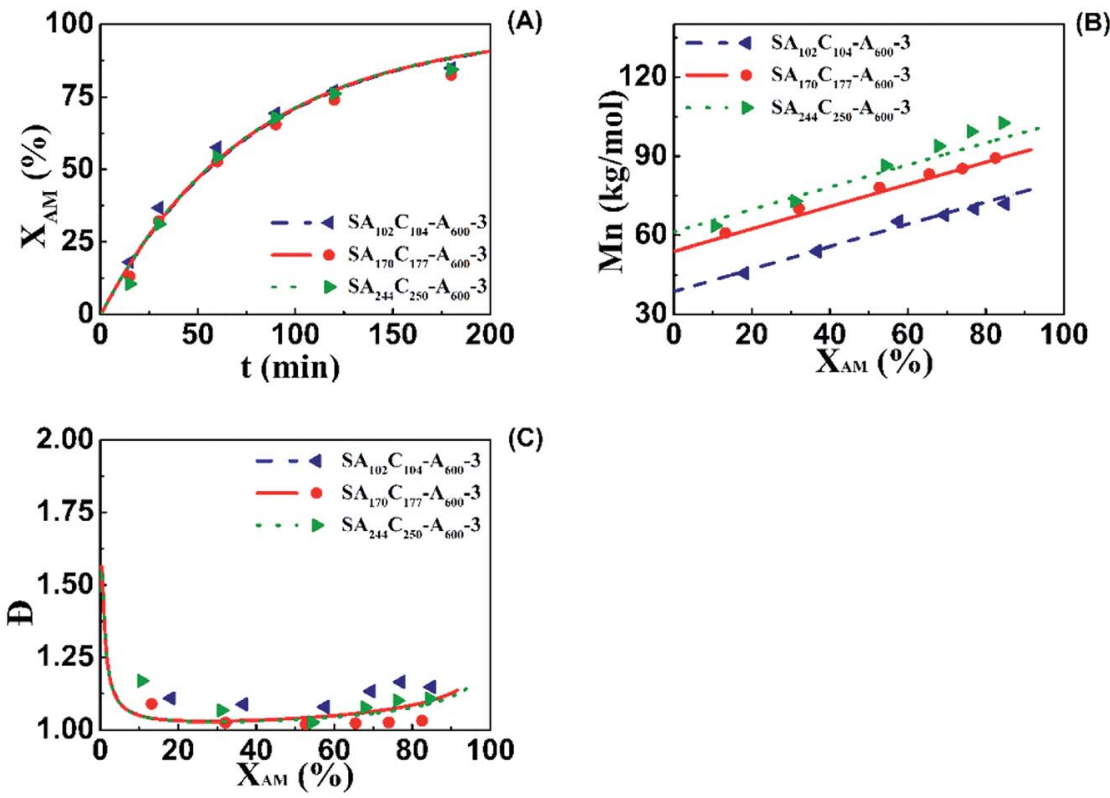

(C)

Fig. 6 Model-predicted and experimental polymerization kinetics for aqueous RAFT solution polymerization of AM using mCTAs of various chain lengths. Plots show (A) AM conversion versus polymerization time, (B) number-average molecular weight versus AM conversion, and (C) dispersity versus AM conversion. Experimental conditions: $[\mathrm{AM}]_{0} /[\mathrm{mCTA}]_{0} /[\mathrm{Va}-044]_{0}=1200 / 2 / 1,[\mathrm{AM}]_{0}=0.423 \mathrm{mM}, \mathrm{pH}=5.0$, sodium acetate/ acetate acid as buffer solution, and $t=50^{\circ} \mathrm{C}$. The lines are model-predicted results while the points are experimental data. 
Table 3 Experimental conditions and results of aqueous RAFT dispersion polymerization of AM using mCTAs ${ }^{a}$

\begin{tabular}{|c|c|c|c|c|c|c|c|c|}
\hline Run & mCTA & $\begin{array}{l}T \\
\left({ }^{\circ} \mathrm{C}\right)\end{array}$ & {$[\mathrm{AM}]_{0}(\mathrm{wt} \%)$} & $X_{\mathrm{AM}}^{b}(\%)$ & Chain structure $^{c}$ & $\mathrm{Mn}^{\text {The, }, d}\left(\mathrm{~kg} \mathrm{~mol}^{-1}\right)$ & $\mathrm{Mn}^{\mathrm{GPC}, e}\left(\mathrm{~kg} \mathrm{~mol}^{-1}\right)$ & $D^{e}$ \\
\hline $\mathrm{DA}_{170} \mathrm{C}_{177^{-}}-6-45^{g}$ & M3 & 45 & 6.0 & 57.4 & 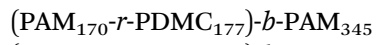 & 73.3 & 71.4 & 1.2 \\
\hline $\mathrm{DA}_{170} \mathrm{C}_{177}-6-55$ & M3 & 55 & 6.0 & 96.5 & $\left(\mathrm{PAM}_{170}-r-\mathrm{PDMC}_{177}\right)-b-\mathrm{PAM}_{579}$ & 89.9 & 87.8 & 1.3 \\
\hline $\mathrm{DA}_{206} \mathrm{C}_{143}-6-50$ & M2 & 50 & 6.0 & 91.6 & $\left(\mathrm{PAM}_{206}-r-\mathrm{PDMC}_{143}\right)-b-\mathrm{PAM}_{550}$ & 82.7 & 82.7 & 1.2 \\
\hline $\mathrm{DA}_{189} \mathrm{C}_{158}-6-50$ & $\mathbf{M} 7^{f}$ & 50 & 6.0 & 92.8 & $\left(\mathrm{PAM}_{189}-r-\mathrm{PDMC}_{158}\right)-b-\mathrm{PAM}_{557}$ & 85.8 & 90.9 & 1.1 \\
\hline $\mathrm{DA}_{244} \mathrm{C}_{250}-4.2-50$ & M6 & 50 & 4.2 & 94.2 & $\left(\mathrm{PAM}_{244}-r-\mathrm{PDMC}_{250}\right)-b-\mathrm{PAM}_{565}$ & 109.3 & 104.6 & 1.2 \\
\hline
\end{tabular}

${ }^{a}$ All runs had $[\mathrm{AM}]_{0} /[\mathrm{mCTA}]_{\mathrm{o}} /[\mathrm{Va}-044]_{0}=1200 / 2 / 1, \mathrm{AS}=28 \mathrm{wt} \%$, and $t=2 \mathrm{~h} .{ }^{b}$ AM conversions were determined by brominate titration method. ${ }^{c}$ Resulting polymer chain structures based on the AM conversions and mCTA chain structures. ${ }^{d}$ Theoretical number-average molecular weights estimated from number-average molecular weights of mCTAs calculated from ${ }^{1} \mathrm{H}$ NMR spectra and PAM block lengths estimated from AM conversions. ${ }^{e}$ Number-average molecular weights and dispersities were determined by GPC. ${ }^{f}$ An AM/DMC random copolymer with Mn ${ }^{\mathrm{GPC}}=$ $46.3 \mathrm{~kg} \mathrm{~mol}{ }^{-1}, D=1.2$, and $C=45.5 \%$ produced by aqueous RAFT solution copolymerization. ${ }^{g}$ Sample code DA ${ }_{170} \mathrm{C}_{177^{-}}-6-45$ represents a RAFT dispersion copolymerization run using $\mathrm{PAM}_{170}-r$-PDMC 177 as mCTA, $6.0 \mathrm{wt} \%$ AM content and $T=45{ }^{\circ} \mathrm{C}$.

propagation radical concentrations resulted in greater $\mathrm{AM}$ conversion.

\section{Model-predicted and experimental polymerization kinetics}

The effect of the extended PAM block length on aqueous RAFT solution polymerization using M3 as mCTA was predicted using the model and validated with experimental data, as shown in Fig. 5. The ratios of $[\mathrm{AM}]_{0} /[\mathrm{M} 3]_{0}$ were $300 / 1\left(\mathrm{SA}_{170} \mathrm{C}_{177}-\mathrm{A}_{300}-3\right)$, $600 / 1\left(\mathrm{SA}_{170} \mathrm{C}_{177}-\mathrm{A}_{600}-3\right)$, and $1200 / 1\left(\mathrm{SA}_{170} \mathrm{C}_{177}-\mathrm{A}_{1200}-3\right)$. It can be seen that the model predictions are in good agreement with the experimental data. Run $\mathrm{SA}_{170} \mathrm{C}_{177}-\mathrm{A}_{300}-3$ had the lowest polymerization rate as a result of having the shortest CPAM length. With the increase of the extended PAM block length from Run $\mathrm{SA}_{170} \mathrm{C}_{177}-\mathrm{A}_{300}-3$ to $\mathrm{SA}_{170} \mathrm{C}_{177}-\mathrm{A}_{1200}-3$, the polymerization rate increased while maintaining good control characteristics.

Viscosities of CPAM samples at 60 min having different extended PAM blocks ranging from 300 to 1200 units were 10.7 $\mathrm{mPa} \mathrm{s}\left(X=26.1 \%, \mathrm{SA}_{170} \mathrm{C}_{177}-\mathrm{A} 300-3\right), 23.0 \mathrm{mPa} \mathrm{s}(X=52.4 \%$, $\left.\mathrm{SA}_{170} \mathrm{C}_{177}-\mathrm{A} 600-3\right)$, and $61.7 \mathrm{mPa} \mathrm{s}\left(X=59.7 \%, \mathrm{SA}_{170} \mathrm{C}_{177^{-}}-\mathrm{A}_{1200^{-}}\right.$ $3)$. The corresponding Prs estimated from the model were 3.99 $\times 10^{-9}, 7.95 \times 10^{-9}$, and $9.87 \times 10^{-9} \mathrm{~mol} \mathrm{~L}^{-1}$, respectively.
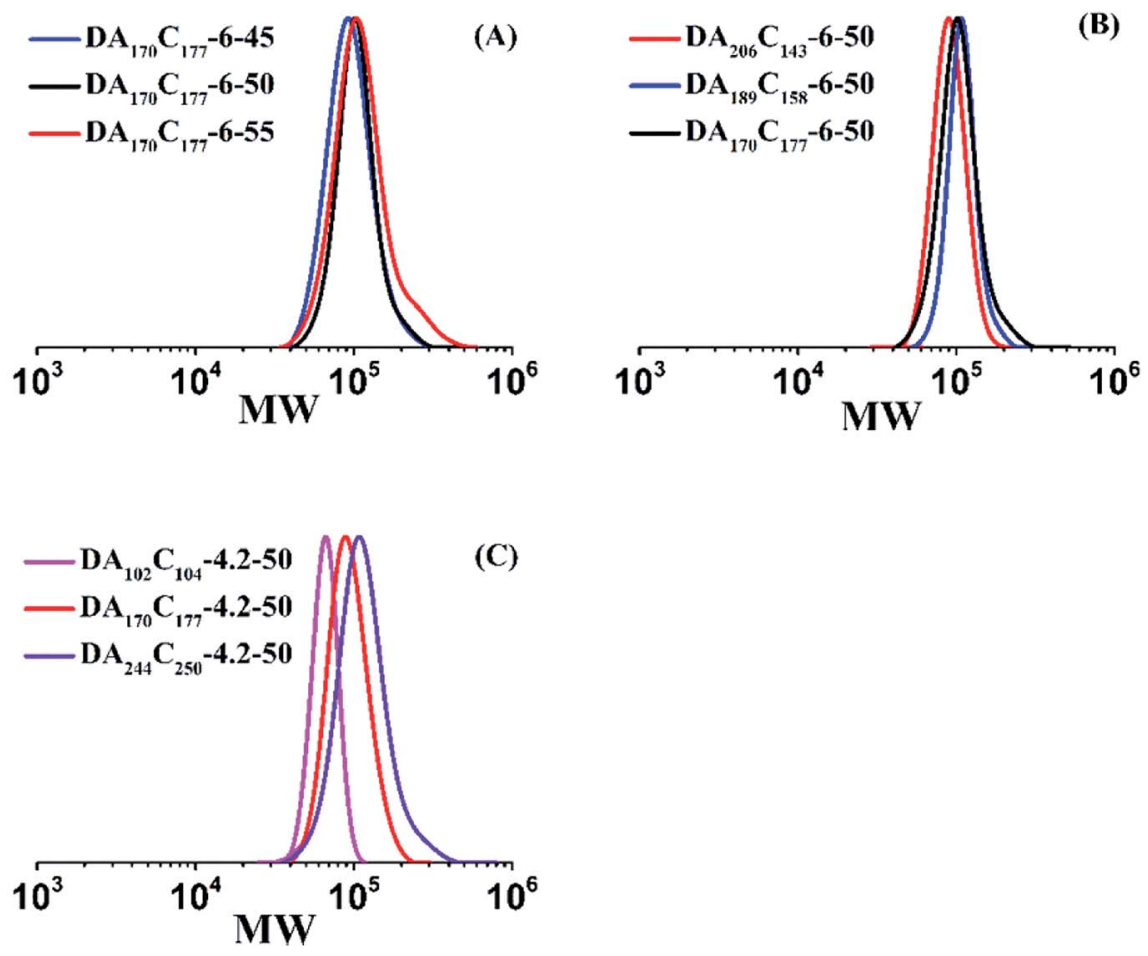

Fig. 7 GPC traces of block CPAM dispersion samples under various experimental conditions including (A) polymerization temperature, (B) cationic degree on mCTA having the same chain length, and (C) molecular weight of mCTA having the same $C$ of $51 \%$. 

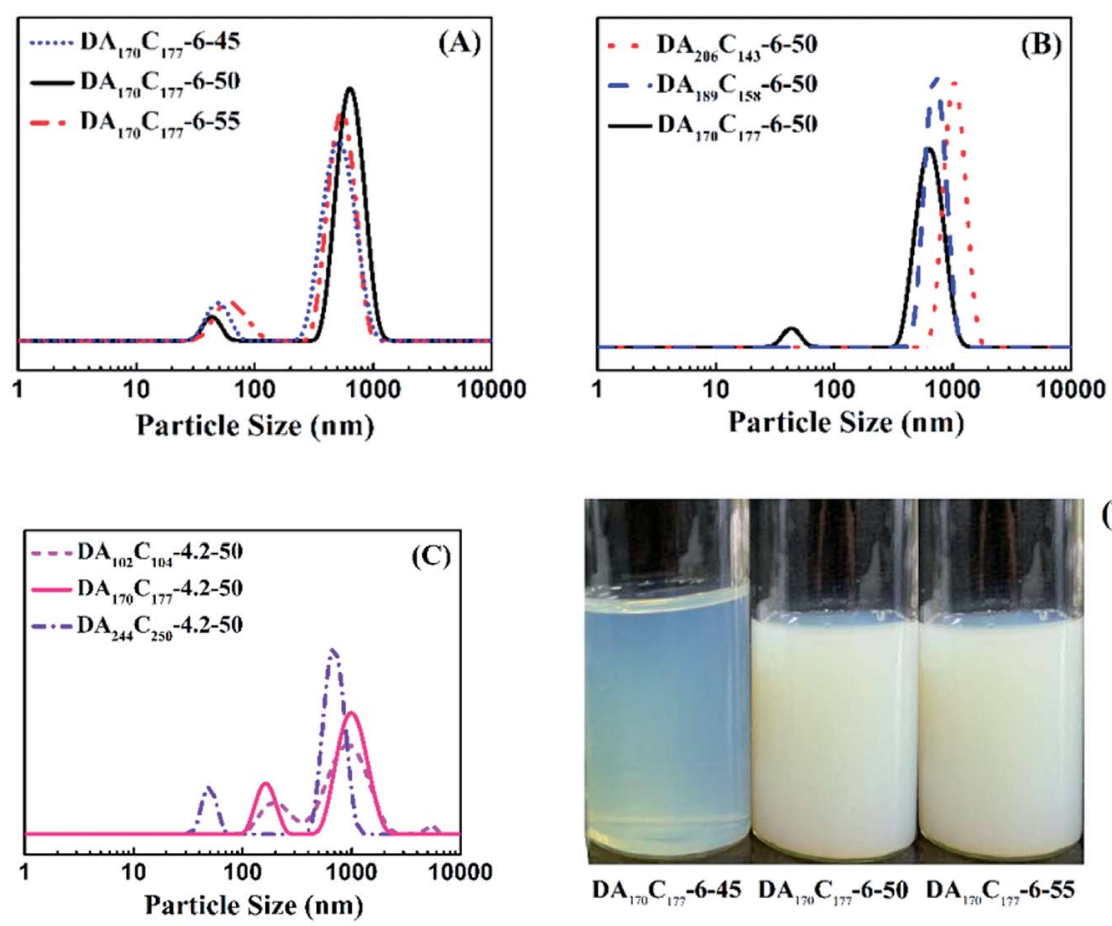

(D)

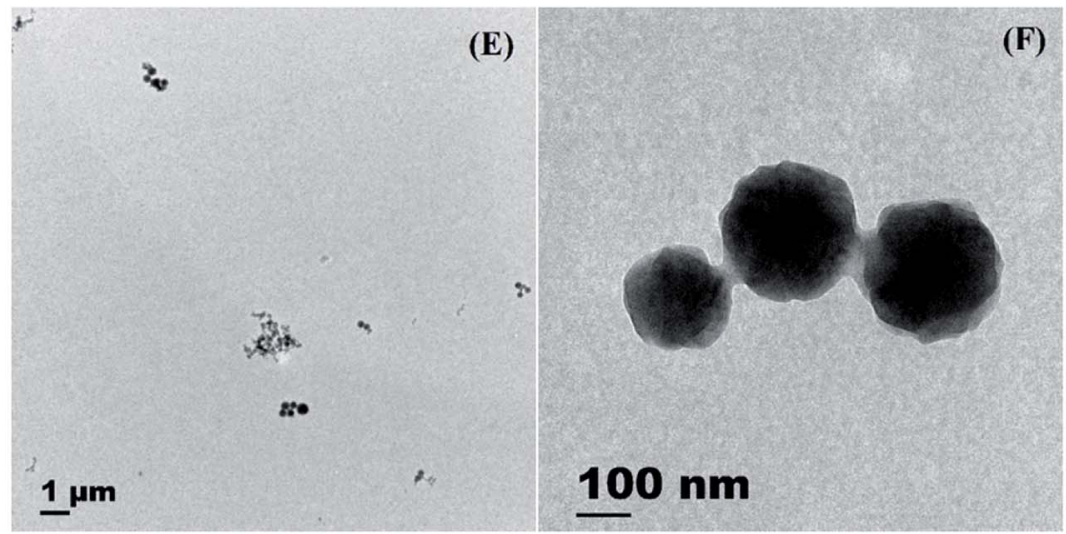

Fig. 8 Appearance of block CPAM dispersion samples and their intensity-based particle size distributions. The samples were synthesized using aqueous RAFT dispersion polymerization under various experimental conditions including a range of (A) polymerization temperatures, (B) cationic degrees on mCTA having the same chain lengths, and (C) molecular weights of mCTA having the same $C_{s}$ of $51 \%$. All the samples were measured at the same temperature as their polymerizations. Also shown are (D) images of Run $D_{170} C_{177}-6-45, D A_{170} C_{177}-6-50$ and $D A_{170} C_{177^{-}}$ 6-55, and Cryo-TEM images of particles from Run $\mathrm{DA}_{102} \mathrm{C}_{104}-4.2-50$ under (E) low and (F) high magnification.

Viscosities and Prs of the samples at $32 \%$ conversion were 12.7, 14.2 , and $23.7 \mathrm{mPa}$ s and $3.74 \times 10^{-9}, 8.24 \times 10^{-9}$, and $10.3 \times$ $10^{-9} \mathrm{~mol} \mathrm{~L}^{-1}$, respectively, indicating that longer CPAM chain lengths produce higher solution viscosity and enhanced the diffusion control, promoting propagation.

The influence of mCTA chain length on aqueous RAFT AM solution polymerization was also examined by model prediction and experiment. Three runs having the same $C$ of $51 \%$ but different number-average molecular weights ranging from 28.8 $\left(\mathrm{SA}_{102} \mathrm{C}_{104}-\mathrm{A}_{600}-3\right), 48.8\left(\mathrm{SA}_{170} \mathrm{C}_{177}-\mathrm{A}_{600}-3\right)$ to $69.2 \mathrm{~kg} \mathrm{~mol}^{-1}$ $\left(\mathrm{SA}_{244} \mathrm{C}_{250}-\mathrm{A}_{600}-3\right)$. Both model-predicted and experimental conversions, molecular weights and distributions are plotted in Fig. 6. Good agreement between the model prediction and experiment further confirm the reliability of the model. The trend for conversions versus polymerization times in three runs is almost overlapping, suggesting the chain length of mCTA had little influence on the kinetics. The narrow dispersities for the three runs indicate good polymerization control for the mCTAs at different chain lengths.

\section{Aqueous RAFT dispersion polymerization of AM using mCTA}

The AM/DMC random copolymers were further used as MCTA and stabilizer for preparing block CPAMs via aqueous RAFT dispersion polymerization of AM. Eight runs were polymerized at a ratio of $[\mathrm{AM}]_{\mathrm{o}} /[\mathrm{mCTA}]_{\mathrm{o}} /[\mathrm{Va}-044]_{0}=1200 / 2 / 1$ and $28 \mathrm{wt} \%$ of ammonium sulfate for $2 \mathrm{~h}$. Various experimental conditions including polymerization temperatures, mCTA cationic degrees 
and chain lengths were studied as shown in Table $3 .{ }^{1} \mathrm{H}$ NMR spectrum of Run $\mathrm{DA}_{170} \mathrm{C}_{177}-6-45$ is given in Fig. S3 of the ESI. $\dagger$ All runs had AM conversions between 57.4-96.5\%, molecular weights close to the theoretical values, and dispersities within 1.3 (see GPC traces given in Fig. 7), suggesting good control of mCTA chain extension. During polymerizations, phase separations occurred, and dispersion systems were formed. The products had a milky appearance as shown in Fig. 8. The particle sizes of the samples were determined by DLS. Their $Z$ average particle size distributions are provided in Fig. 8. Most samples except Run $\mathrm{DA}_{206} \mathrm{C}_{143}-6-50$ and $\mathrm{DA}_{189} \mathrm{C}_{158^{-6}} 6-50$ had two peaks with one peak at approximately $20-200 \mathrm{~nm}$ contributed by separated phase particles, and another peak approximately $1000 \mathrm{~nm}$ attributed to the aggregation of particles. Particle morphology of Run $\mathrm{DA}_{102} \mathrm{C}_{104}-4.2-50$ was further characterized with Cryo-TEM. TEM images are shown in Fig. 8E and F. The particles with approximately $100 \mathrm{~nm}$ and the particle aggregates having a size of approximately $1 \mu \mathrm{m}$ can be observed, which is consistent with the DLS results and confirms particle aggregation.

The products were stable and could be stored at room temperature for more than one month. Moreover, the solid content in the dispersion system went up to $12.9 \mathrm{wt} \%$ (Run $\left.\mathrm{DA}_{170} \mathrm{C}_{177}-6-50\right)$ with an apparent viscosity of $23.4 \mathrm{mPa} \mathrm{s}$, in comparison to the solution system having similar chain structure and length at a solid content of $6.4 \mathrm{wt} \%$ (Run $\mathrm{SA}_{170} \mathrm{C}_{177^{-}}$ $\left.\mathrm{A}_{600}-3\right)$ with an apparent viscosity of $108.5 \mathrm{mPa}$ s. We also synthesized a solution sample having the same solid content (12.9 wt\%), chain structure and length as Run $\mathrm{DA}_{170} \mathrm{C}_{177}-6-50$. This sample had a viscosity of $750.2 \mathrm{mPa} \mathrm{s}$, indicating that viscosity can be limited and suggesting that CPAM can be prepared at a high solids content using dispersion polymerization.

The aqueous RAFT dispersion polymerizations of AM using mCTA were carried out at $45{ }^{\circ} \mathrm{C}\left(\mathrm{DA}_{170} \mathrm{C}_{177}-6-45\right), 50{ }^{\circ} \mathrm{C}$

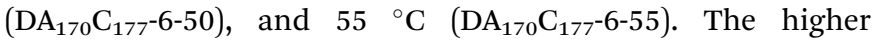
temperature accelerated polymerizations. The AM conversion went up, from $57.4 \%$ at $45{ }^{\circ} \mathrm{C}$ to $96.5 \%$ at $55{ }^{\circ} \mathrm{C}$, and $D$ rose slightly. However, polymerization temperature had little influence on the particle size distributions of the samples. All three samples had two peaks with one approximately $20-100 \mathrm{~nm}$ and another around $1000 \mathrm{~nm}$.

Table 4 Elementary reactions in aqueous RAFT solution polymerization

Elementary

reaction Scheme

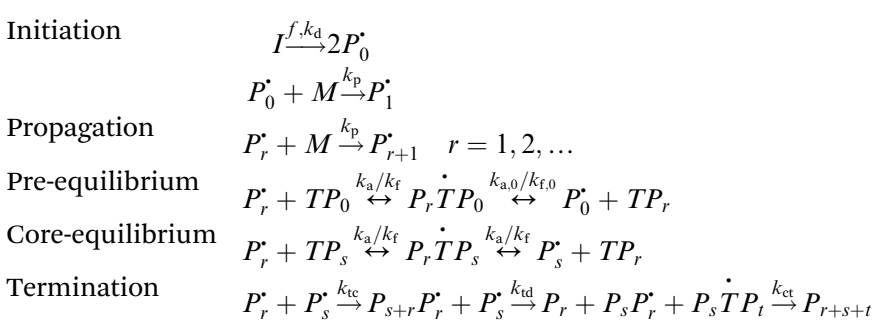

Table 5 Definition of moments for each chain species

\begin{tabular}{ll}
\hline Type of chains & Definition of Moments \\
\hline Propagating radical & $Y_{\mathrm{m}}=\sum_{r=2}^{\infty} r^{\mathrm{m}}\left[P_{r}^{*}\right]$ \\
Dormant & $Q_{\mathrm{m}}^{\mathrm{T}}=\sum_{r=2}^{\infty} r^{\mathrm{m}}\left[T P_{r}\right]$ \\
Intermediate radical & $Y_{\mathrm{m}}=\frac{1}{2} \sum_{r=2}^{\infty} r^{\mathrm{m}} \sum_{s=2}^{r-2}\left[P_{s} \dot{T} P_{r-s}\right]$ \\
& $Y_{\mathrm{m}, \mathrm{n}}^{\mathrm{T}}=\sum_{r=2}^{\infty} r^{\mathrm{m}} s^{\mathrm{n}} \sum_{s=2}^{r-2}\left[P_{r} \dot{T} P_{s}\right]$ \\
Dead & $Q_{\mathrm{m}}=\sum_{r=2}^{\infty} r^{\mathrm{m}}\left[P_{r}\right]$
\end{tabular}

Three mCTAs having the same chain lengths of 348 but different $C_{\mathrm{s}}$ of $41.0 \%\left(\mathrm{DA}_{206} \mathrm{C}_{143}-6-50\right), 45.5 \%\left(\mathrm{DA}_{189} \mathrm{C}_{158}-6-50\right)$, and $51.0 \%\left(\mathrm{DA}_{170} \mathrm{C}_{177}-6-50\right)$ were used for the dispersion polymerization. In RAFT solution polymerization, the cationic degree did not affect the kinetics, which was also found in RAFT dispersion polymerizations of AM. However, the charge density in mCTA had a significant effect on phase separation since the positive charge of mCTA made the dispersion stable. When mCTA with lower $C$ was used, the repulsive force between particles decreased. Run $\mathrm{DA}_{206} \mathrm{C}_{143}-6-50$ had $Z$-average particle size $\left(D_{\mathrm{Z}}\right)$ of $1057 \mathrm{~nm}$. With the increase of $C$ on mCTA to $45.5 \%$, the particle sizes of the dispersion phase became smaller with $D_{\mathrm{Z}}=723.0 \mathrm{~nm}$. The increment of $C$ on mCTA to $51.0 \%$ further modified the particle size distribution with it becoming bimodal with a $D_{\mathrm{Z}}$ at $43.8 \mathrm{~nm}$ and another, presumably for the aggregates at $656.4 \mathrm{~nm}$.

Also studied was the effect of mCTA chain length for a fixed $C$ of $51 \%$ on RAFT dispersion polymerizations. The molecular weights of mCTAs ranged from $28.8 \mathrm{~kg} \mathrm{~mol}{ }^{-1}\left(\mathrm{DA}_{102} \mathrm{C}_{104}-4.2-\right.$ $50), 48.8 \mathrm{~kg} \mathrm{~mol}{ }^{-1}\left(\mathrm{DA}_{170} \mathrm{C}_{177}-4.2-50\right)$, to $69.2 \mathrm{~kg} \mathrm{~mol} \mathrm{~m}^{-1}$ $\left(\mathrm{DA}_{244} \mathrm{C}_{250}-4.2-50\right)$. Longer mCTA chains increased the viscosity of the polymerization system, resulting in higher conversions (from 68.6 to $94.2 \%$ ) and CPAM molecular weight (from 82.5 to $104.6 \mathrm{~kg} \mathrm{~mol}^{-1}$ ) due to diffusion-controlled effect. The longer mCTA ( $\left.\mathrm{DA}_{244} \mathrm{C}_{250}-4.2-50\right)$ was beneficial to stabilizing the polymerization system and produced particles having the smallest particles $\left(D_{\mathrm{Z}}=49.73 \mathrm{~nm}\right)$. When the mCTA became shorter, the formed particles became larger, $D_{\mathrm{Z}}$ of $165.7 \mathrm{~nm}$ for Run $\mathrm{DA}_{170} \mathrm{C}_{177}-4.2-50$ and $210.5 \mathrm{~nm}$ for Run $\mathrm{DA}_{102} \mathrm{C}_{104}-4.2-50$, respectively, and more particle aggregation occurred.

\section{Conclusions}

Random copolymers of AM and DMC were synthesized via RAFT solution copolymerization at a pH of 5 with BCPA as CTA. The copolymers were used as macro RAFT chain transfer agent mCTA and stabilizer for chain extension in aqueous RAFT dispersion polymerization of AM. Random copolymers had $C$ values ranging from 19.9 to $61.7 \%, M_{\mathrm{n}}$ values ranging from 28.8 to $69.2 \mathrm{~kg} \mathrm{~mol}^{-1}$, and $Ð$ values of less than 1.2. The aqueous 
Table 6 Kinetic equations for chain species

\begin{tabular}{lr}
\hline Type of chains & Mass balance equation \\
\hline Propagating radical chains & $\frac{\mathrm{d}\left[P_{r}^{*}\right]}{\mathrm{d} t}=k_{\mathrm{p}}\left[P_{r-1}^{*}\right][M]-k_{\mathrm{p}}\left[P_{r}^{*}\right][M]-k_{\mathrm{a}}\left[P_{r}^{*}\right]\left(\left[T P_{0}\right]+\sum_{s}\left[T P_{s}\right]\right)+\frac{1}{2} k_{\mathrm{f}}\left(\left[P_{r} \dot{T} P_{0}\right]+\frac{1}{2} \sum_{s}\left[P_{r} \dot{T} P_{s}\right]\right)$ \\
& $-\sum_{s}\left(k_{\mathrm{tc}}+k_{\mathrm{td}}\right)\left[P_{r}^{*}\right]\left[P_{s}^{*}\right]-k_{\mathrm{ct}}\left[P_{r}^{*}\right]\left(\sum_{s}\left[P_{s} \dot{T} P_{0}\right]-\sum_{s} \sum_{t}\left[P_{s} \dot{T} P_{t}\right]\right)$ \\
Dormant chains & $\frac{\mathrm{d}\left[T P_{r}\right]}{\mathrm{d} t}=\frac{1}{2}\left(k_{\mathrm{f}, 0}\left[P_{r} \dot{T} P_{0}\right]+\frac{1}{2} \sum_{s} k_{\mathrm{f}}\left[P_{r} \dot{T} P_{s}\right]\right)-\left(k_{\mathrm{a}, 0}\left[P_{0}^{*}\right]+\sum_{s} k_{\mathrm{a}}\left[P_{s}^{*}\right]\right)\left[T P_{r}\right]$ \\
Primary intermediate radical & $\frac{\mathrm{d}\left[P_{r} \dot{T} P_{0}\right]}{\mathrm{d} t}=k_{\mathrm{a}, 0}\left[P_{0}^{*}\right]\left[T P_{r}\right]+k_{\mathrm{a}}\left[P_{r}^{*}\right]\left[T P_{0}\right]-\frac{1}{2}\left(k_{\mathrm{f}, 0}+k_{\mathrm{f}}\right)\left[P_{r} \dot{T} P_{0}\right]-\sum_{s} k_{\mathrm{ct}}\left[P_{s}^{*}\right]\left[P_{r} \dot{T} P_{0}\right]$ \\
chains & $\frac{\mathrm{d}\left[P_{r} T P_{s}\right]}{\mathrm{d} t}=k_{\mathrm{a}}\left[P_{r}^{*}\right]\left[T P_{s}\right]+k_{\mathrm{a}}\left[P_{s}^{*}\right]\left[T P_{r}\right]-k_{\mathrm{f}}\left[P_{r} \dot{T} P_{s}\right]-\sum_{t} k_{\mathrm{ct}}\left[P_{t}^{*}\right]\left[P_{r} \dot{T} P_{s}\right]$ \\
& $\frac{\mathrm{d}\left[P_{r}\right]}{\mathrm{d} t}=\sum_{l} \sum_{s=0}^{r} k_{t c}\left[P_{s}^{*}\right]\left[P_{r-s}^{*}\right]+\sum_{s} k_{\mathrm{td}}\left[P_{r}^{*}\right]\left[P_{s}^{*}\right]+\sum_{s=0}^{r} k_{\mathrm{ct}}\left[P_{s}^{*}\right]\left[P_{r-s} \dot{T} P_{0}\right]+\sum_{s=0}^{r} k_{\mathrm{ct}}\left[P_{r-s}^{*}\right] \sum_{t=0}^{s}\left[P_{t} \dot{T} P_{s-t}\right]$
\end{tabular}

RAFT polymerizations of AM using random copolymers as mCTAs with $[\mathrm{mCTA}]_{0} /[\mathrm{Va}-044]_{0}=2 / 1$ were conducted. It was observed that the progress of narrow-distributed GPC traces of resulted block CPAMs $(\nexists \leq 1.2)$ with polymerization times and existence of linear relationships between $-\ln \left(1-X_{\mathrm{AM}}\right)$ and $t$, and $M_{\mathrm{w}}$ and $X_{\mathrm{AM}}$, suggesting a controlled characteristic in AM block extension with AM/DMC random copolymers as mCTAs. The cationic degrees and chain lengths of mCTAs had little influence on the chain propagation of AM. When the AM addition content was more than $3.0 \%$ and the PAM block was extended from 300 to 1200 units, the polymerization rate increased rapidly due to diffusion control effect. In order to better understand the chain extension kinetics in aqueous solution, a model using the method of moments with the consideration of diffusion control effect was developed. Experimental data were well fit with model predictions. The AM/DMC random copolymers were used as stabilizer for aqueous RAFT dispersion polymerization of AM, to produce the block CPAM precursors at an elevated solid content. Stable milky CPAM dispersions were obtained with particle sizes from 10 to $200 \mathrm{~nm}$ and aggregates of approximately $1000 \mathrm{~nm}$, which were stable on storing at room temperature for more than 1 month. The resulting block CPAMs had $Ð$ values of less than 1.3 with molecular weight ranging from 58.1 to $109.3 \mathrm{~kg} \mathrm{~mol}^{-1}$. Effects of temperature (45 to $55{ }^{\circ} \mathrm{C}$ ), mCTA cationic degree (41.0 to $51.0 \%$ ) and molecular weights (28.8 to $69.2 \mathrm{~kg} \mathrm{~mol}^{-1}$ ) on aqueous dispersion were investigated. High polymerization temperature promoted the polymerization but had little influence on particle size, while the charge density on mCTA had little effect on the reaction rate but had a great impact on phase separation. With the increase of charge density from 41.0 to $51.0 \%$ on mCTAs, the particle sizes of the dispersion phase became smaller and formed fewer aggregates. Longer mCTA chains resulted in higher conversions and produced the particles having a smaller particle size and less aggregation. The results indicate that the aqueous RAFT dispersion polymerization using random copolymers of AM and DMC at moderate cationic degrees as stabilize and mCTA is a suitable approach in synthesizing CPAM block precursors at an elevated solid content.

\section{Appendix}

\section{Reaction mechanism of RAFT aqueous polymerization}

A kinetic model of aqueous RAFT solution polymerization of AM mediated by mCTA was developed based on the elementary reactions listed in Table 4 . Chain transfer reactions to monomer and solvent were not considered. The number-average chain length $\left(\bar{r}_{\mathrm{N}}\right)$, weight-average chain length $\left(\bar{r}_{\mathrm{W}}\right), \emptyset$, and $M_{\mathrm{n}}$ were calculated using eqn (A1)-(A4) using the method of moments. ${ }^{73,74}$ The moments of various chain species are defined in Table 5. The specific derivations for the balance of species and moments are shown in Tables 6 and 7.

$$
\begin{array}{r}
\bar{r}_{\mathrm{N}}=\frac{Y_{1}+Y_{1}^{\mathrm{T}}+Q_{1}+Q_{1}^{\mathrm{T}}}{Y_{0}+Y_{0}^{\mathrm{T}}+Q_{0}+Q_{0}^{\mathrm{T}}}+\bar{r}_{\mathrm{N}, \mathrm{mCTA}} \\
\bar{r}_{\mathrm{W}}=\frac{Y_{2}+Y_{2}^{\mathrm{T}}+Q_{2}+Q_{2}^{\mathrm{T}}}{Y_{1}+Y_{1}^{\mathrm{T}}+Q_{1}+Q_{1}^{\mathrm{T}}}+\bar{r}_{\mathrm{W}, \mathrm{mCTA}} \\
D=\frac{\bar{r}_{\mathrm{W}}}{\bar{r}_{\mathrm{N}}} \\
M_{\mathrm{n}}=\left(\bar{r}_{\mathrm{N}}-\bar{r}_{\mathrm{N}, \mathrm{mCTA}}\right) m_{\mathrm{AM}}+M_{\mathrm{n}, \mathrm{mCTA}}
\end{array}
$$

where $\bar{r}_{\mathrm{N}, \mathrm{MCTA}}$ and $\bar{r}_{\mathrm{W}, \mathrm{MCTA}}$ represent the contribution made by mCTA, respectively. $m_{\mathrm{AM}}$ is the molecular weight of AM.

\section{Diffusion-controlled termination model}

With the polymerization proceeded, the amount and length of polymeric chains would increase, which lead to increased viscosity. As a result, reactions involved in long chains could become diffusion controlled, which is quite common in a radical polymerization process. ${ }^{75,76}$ Here we adopted a semiempirical equation, ${ }^{77-79}$ only for diffusion-controlled 
Table 7 Differential equations of moments

\begin{tabular}{ll}
$\begin{array}{l}\text { Zeroth-order } \\
\text { moments }\end{array}$ & Mass balance equation \\
\hline $\begin{array}{l}\text { Propagating } \\
\text { radical chains }\end{array}$ & $\frac{\mathrm{d} Y_{0}}{\mathrm{~d} t}=2 f k_{\mathrm{d}}[I]+k_{\mathrm{f}} Y_{0}^{\mathrm{T}}-k_{\mathrm{a}} Y_{0} Q_{0}^{\mathrm{T}}$ \\
$\begin{array}{l}\text { Intermediate } \\
\text { radical chains }\end{array}$ & $\frac{\mathrm{d} Y_{0}^{\mathrm{T}}}{\mathrm{d} t}=k_{0} Y_{0}-k_{\mathrm{tc}} Y_{0} Y_{0}-k_{\mathrm{ct}} Y_{0} Y_{0}^{\mathrm{T}}-k_{\mathrm{f}} Y_{0}^{\mathrm{T}}-k_{\mathrm{ct}} Y_{0} Y_{0}^{\mathrm{T}}$ \\
Dormant chains & $\frac{\mathrm{d} Q_{0}^{\mathrm{T}}}{\mathrm{d} t}=k_{\mathrm{f}} Y_{0}^{\mathrm{T}}-k_{\mathrm{a}} Y_{0} Q_{0}^{\mathrm{T}}$ \\
Dead chains & $\frac{\mathrm{d} Q_{0}}{\mathrm{~d} t}=k_{\mathrm{td}} Y_{0} Y_{0}+\frac{1}{2} k_{\mathrm{tc}} Y_{0} Y_{0}+k_{\mathrm{ct}} Y_{0} Y_{0}^{\mathrm{T}}$ \\
\hline
\end{tabular}

\begin{tabular}{ll}
$\begin{array}{l}\text { First-order } \\
\text { moments }\end{array}$ & Mass balance equation \\
\hline $\begin{array}{l}\text { Propagating } \\
\text { radical chains }\end{array}$ & $\frac{\mathrm{d} Y_{1}}{\mathrm{~d} t}=k_{\mathrm{p}} Y_{0}[M]+\frac{1}{2} k_{\mathrm{f}} Y_{1}^{\mathrm{T}}-k_{\mathrm{a}} Y_{1} Q_{0}^{\mathrm{T}}$ \\
$\quad k_{\mathrm{td}} Y_{0} Y_{1}-k_{\mathrm{tc}} Y_{0} Y_{1}-k_{\mathrm{ct}} Y_{1} Y_{0}^{\mathrm{T}}$ \\
$\begin{array}{l}\text { Intermediate } \\
\text { radical chains } \\
\text { Dormant chains }\end{array}$ & $\frac{\mathrm{d} Y_{1}^{\mathrm{T}}}{\mathrm{d} t}=k_{\mathrm{a}} Y_{1} Q_{0}^{\mathrm{T}}+k_{\mathrm{a}} Y_{0} Q_{1}^{\mathrm{T}}-k_{\mathrm{f}} Y_{1}^{\mathrm{T}}-k_{\mathrm{ct}} Y_{0} Y_{1}^{\mathrm{T}}$ \\
Dead chains & $\frac{\mathrm{d} Q_{1}^{\mathrm{T}}}{\mathrm{d} t}=\frac{1}{2} k_{\mathrm{f}} Y_{1}^{\mathrm{T}}-k_{\mathrm{a}} Y_{0} Q_{1}^{\mathrm{T}}$ \\
\hline
\end{tabular}

Second-order

moments

Mass balance equation

Propagating

radical chains

$\frac{\mathrm{d} Y_{2}}{\mathrm{~d} t}=k_{\mathrm{p}} Y_{0}[M]+2 k_{\mathrm{p}} Y_{1}[M]+\frac{1}{2} k_{\mathrm{f}} Y_{2,0}^{\mathrm{T}}-k_{\mathrm{a}} Y_{2} Q_{0}^{\mathrm{T}}$

Intermediate

radical chains

$$
-k_{\mathrm{td}} Y_{0} Y_{2}-k_{\mathrm{tc}} Y_{0} Y_{2}-k_{\mathrm{ct}} Y_{2} Y_{0}^{\mathrm{T}}
$$

$\frac{\mathrm{d} Y_{2}^{\mathrm{T}}}{\mathrm{d} t}=k_{\mathrm{a}} Y_{2} Q_{0}^{\mathrm{T}}+2 k_{\mathrm{a}} Y_{1} Q_{1}^{\mathrm{T}}+k_{\mathrm{a}} Y_{0} Q_{2}^{\mathrm{T}}$

$-k_{\mathrm{f}} Y_{2}^{\mathrm{T}}-k_{\mathrm{ct}} Y_{0} Y_{2}^{\mathrm{T}}$

$\frac{\mathrm{d} Y_{2,0}^{\mathrm{T}}}{\mathrm{d} t}=k_{\mathrm{a}} Y_{2} Q_{0}^{\mathrm{T}}+k_{\mathrm{a}} Y_{0} Q_{2}^{\mathrm{T}}-k_{\mathrm{f}} Y_{2,0}^{\mathrm{T}}-k_{\mathrm{ct}} Y_{0} Y_{2,0}^{\mathrm{T}}$

Dormant chains $\quad \frac{\mathrm{d} Q_{2}^{\mathrm{T}}}{\mathrm{d} t}=\frac{1}{2} k_{\mathrm{f}} Y_{2,0}^{\mathrm{T}}-k_{\mathrm{a}} Y_{0} Q_{2}^{\mathrm{T}}$

Dead chains

$$
\frac{\mathrm{d} Q_{2}}{\mathrm{~d} t}=k_{\mathrm{td}} Y_{0} Y_{2}+k_{\mathrm{tc}} Y_{0} Y_{2}+k_{\mathrm{tc}} Y_{1} Y_{1}+k_{\mathrm{ct}} Y_{0} Y_{2}^{\mathrm{T}}
$$$$
+2 k_{\mathrm{ct}} Y_{1} Y_{1}^{\mathrm{T}}+k_{\mathrm{ct}} Y_{2} Y_{0}^{\mathrm{T}}
$$

\section{Mass balance equation}

Small molecule

$$
\frac{\mathrm{d}[I]}{\mathrm{d} t}=-k_{\mathrm{d}}[I] \frac{\mathrm{d}[M]}{\mathrm{d} t}=-k_{\mathrm{p}}[M] Y_{0}
$$

termination reaction because the termination rate constants are several order of magnitude higher than the other kinetic rate constants.

$$
\begin{gathered}
\frac{1}{k_{\mathrm{t}}}=\frac{1}{k_{\mathrm{t}, \mathrm{C}}}+\frac{1}{k_{\mathrm{t}, \mathrm{D}}} \\
k_{\mathrm{t}, \mathrm{D}}=k_{\mathrm{t}, \mathrm{D}}^{0}\left(\bar{r}_{\mathrm{N}}\right)^{-a} \exp \left(\frac{-b}{v_{\mathrm{f}}}\right) \\
v_{\mathrm{f}}=\left[0.025+\alpha_{\mathrm{p}}\left(T-T_{\mathrm{gp}}\right)\right] \varphi_{\mathrm{p}} \\
+\left[0.025+\alpha_{\mathrm{m}}\left(T-T_{\mathrm{gm}}\right)\right] \varphi_{\mathrm{m}} \\
+\left[0.025+\alpha_{\mathrm{s}}\left(T-T_{\mathrm{gs}}\right)\right] \varphi_{\mathrm{s}}
\end{gathered}
$$

Table 8 Physical property parameters

\begin{tabular}{lll}
\hline Parameters & Values & References \\
\hline$\alpha_{\mathrm{P}}\left(\mathrm{K}^{-1}\right)$ & $4.8 \times 10^{-4}$ & 16 \\
$\alpha_{\mathrm{m}}\left(\mathrm{K}^{-1}\right)$ & $1 \times 10^{-3}$ & 80 \\
$\alpha_{\mathrm{s}}\left(\mathrm{K}^{-1}\right)$ & 0.012 & 81 \\
$T_{\mathrm{gm}}(\mathrm{K})$ & 260 & 84 \\
$T_{\mathrm{gs}}(\mathrm{K})$ & 136 & 84 \\
$T_{\mathrm{gp}}(\mathrm{K})$ & 438 & 82 \\
\hline
\end{tabular}

Table 9 Kinetic rate constants

\begin{tabular}{lll}
\hline Parameters & Values & Ref. \\
\hline$k_{\mathrm{d}}\left(\mathrm{s}^{-1}\right)$ & $4.02 \times 10^{-5}$ & 83 \\
$k_{\mathrm{p}}\left(\mathrm{L} \mathrm{mol} \mathrm{mol}^{-1} \mathrm{~s}^{-1}\right)$ & $4.266 \times 10^{7} \exp (-3909.61 / T)$ & 83 \\
$k_{\mathrm{a}}=k_{a, 0}\left(\mathrm{~L} \mathrm{~mol}^{-1} \mathrm{~s}^{-1}\right)$ & $4 \times 10^{4}$ & This work \\
$k_{\mathrm{f}}=k_{\mathrm{f}, 0}\left(\mathrm{~s}^{-1}\right)$ & $5 \times 10^{3}$ & This work \\
$k_{\mathrm{tc}}\left(\mathrm{L} \mathrm{mol}^{-1} \mathrm{~s}^{-1}\right)$ & $2.0 \times 10^{10} \exp (-1553.01 / \mathrm{T})$ & 83 \\
$k_{\mathrm{t}, \mathrm{D}}^{0}$ & $3 \times 10^{12}$ & This work \\
$a$ & 0.3 & This work \\
$b$ & 0.7 & This work \\
$k_{\mathrm{ct}}$ & $2 \times 10^{6}$ & This work \\
& &
\end{tabular}

where $k_{\mathrm{t}, \mathrm{D}}^{0}, a$, and $b$ are adjustable parameters to correlate the experimental data. The other parameters are obtained from the literature with their physical meanings described in the Table 8.

\section{Author contributions}

The manuscript was written with contributions of all authors. All authors have given approval to the final version of the manuscript.

\section{Conflicts of interest}

There are no conflicts to declare.

\section{Acknowledgements}

This work is financially supported by National Key Research and Development Program of China (2016YFC0206003), and National Natural Science Foundation of China (21420102008, 21536011, 21074116, and 20936006). The authors thank $\mathrm{Mr}$ Eryuan Fang for his assistance in performing GPC analyses at State Key Laboratory of Chemical Engineering (Zhejiang University).

\section{Notes and references}

1 C. S. Lee, J. Robinson and M. F. Chong, Process Saf. Environ. Prot., 2014, 92, 489.

2 K. E. Lee, N. Morad, T. T. Teng and B. T. Poh, Chem. Eng. J., 2012, 203, 370.

3 D. A. Z. Wever, F. Picchioni and A. A. Broekhuis, Prog. Polym. Sci., 2011, 36, 1558.

4 M. Ma and S. Zhu, Colloid Polym. Sci., 1999, 277, 115. 
5 M. Ma and S. Zhu, Colloid Polym. Sci., 1999, 277, 123.

6 R. Subramanian, S. Zhu and R. H. Pelton, Colloid Polym. Sci., 1999, 277, 939.

7 D. Li, S. Zhu, R. H. Pelton and M. Spafford, Colloid Polym. Sci., 1999, 277, 108.

8 Á. Blanco, E. Fuente, M. C. Monte, N. Cortés and C. Negro, Ind. Eng. Chem. Res., 2009, 48, 4826.

9 F. Brouillette, D. Morneau, B. Chabot and C. Daneault, Pulp Pap. Can., 2004, 105, 31.

10 J. Chiefari, Y. K. Chong, F. Ercole, J. Krstina, J. Jeffery, T. P. T. Le, R. T. A. Mayadunne, G. F. Meijs, C. L. Moad, G. Moad, E. Rizzardo and S. H. Thang, Macromolecules, 1998, 31, 5559.

11 Z. Wang, J. He, Y. Tao, L. Yang, H. Jiang and Y. Yang, Macromolecules, 2003, 36, 7446.

12 H. T. Lord, J. F. Quinn, S. D. Angus, M. R. Whittaker, M. H. Stenzel and T. P. Davis, J. Mater. Chem., 2003, 13, 2819.

13 L. Zhang and Y. Chen, Polymer, 2006, 47, 5259.

14 I. Capek and W. Funke, Macromol. Chem., 1990, 191, 121.

15 D. Wang, W.-J. Wang, B.-G. Li and S. Zhu, AIChE J., 2013, 59, 1322.

16 D. Wang, X. Li, W.-J. Wang, X. Gong, B.-G. Li and S. Zhu, Macromolecules, 2012, 45, 28.

17 W.-J. Wang, D. Wang, B.-G. Li and S. Zhu, CN Pat., 101693749B, 2009.

18 W.-J. Wang, D. Wang, B.-G. Li and S. Zhu, CN Pat., 102153714B, 2010.

19 D. B. Thomas, A. J. Convertine, R. D. Hester, A. B. Lowe and C. L. McCormick, Macromolecules, 2004, 37, 1735.

20 D. B. Thomas, A. J. Convertine, L. J. Myrick, C. W. Scales, A. E. Smith, A. B. Lowe, Y. A. Vasilieva, N. Ayres and C. L. McCormick, Macromolecules, 2004, 37, 8941.

21 G. Qi, C. W. Jones and F. J. Schork, Macromol. Rapid Commun., 2007, 28, 1010.

22 K. Vijayakrishna, S. K. Jewrajka, A. Ruiz, R. Marcilla, J. A. Pomposo, D. Mecerreyes, D. Taton and Y. Gnanou, Macromolecules, 2008, 41, 6299.

23 S. S. Eamegdool, M. W. Weible II, B. T. T. Pham, B. S. Hawkett, S. M. Grieve and T. Chan-ling, Biomaterials, 2014, 35, 5549.

24 A. Asadujjaman, B. Kent and A. Bertin, Soft Matter, 2017, 13, 658.

25 M. Hayashi, A. Noro and Y. Matsushita, Macromol. Rapid Commun., 2016, 37, 678.

26 S. Lin, J. Shang and P. Theato, Polym. Chem., 2017, 8, 2619. 27 S. Bai, Y. Wang, B. Liu, Y. Zhu and R. Guo, Colloids Surf., A, 2018, 553, 446.

28 E. Abdollahi, A. Khalafi-Nezhad, A. Mohammadi, M. Abdouss and M. Salami-Kalajahi, Polymer, 2018, 143, 245.

29 X.-M. Wu, L.-L. Wang, Y. Wang, J.-S. Gu and H.-Y. Yu, J. Membr. Sci., 2012, 421-422, 60.

30 R. Ranjan and W. J. Brittain, Macromolecules, 2007, 40, 6217. 31 J. Huang, W.-J. Wang, B.-G. Li and S. Zhu, Macromol. Mater. Eng., 2013, 298, 391.

32 D. Yang, D.-P. Yu, X.-F. Dong, A.-J. Shen, G.-W. Jin, Z.-M. Guo, J.-Y. Yan, M.-Y. Liu and X.-M. Liang, Chin. J. Anal. Chem., 2015, 43, 1439.
33 L. Xiang, W.-J. Wang, B.-G. Li and S. Zhu, Macromol. React. Eng., 2017, 11, 1700023.

34 M. Takara, M. Toyoshima, H. Seto, Y. Hoshino and Y. Miura, Polym. Chem., 2014, 5, 931.

35 L. Xun, J. Qiao, L. Qi, J. Huang and H. Cai, Anal. Methods, 2015, 7, 9906.

36 C. Gupta, M. J. Sverdlove and N. R. Washburn, Soft Matter, 2015, 11, 2691.

37 K. S. Silmore, C. Gupta and N. R. Washburn, J. Colloid Interface Sci., 2016, 466, 91.

38 C. Gupta and N. R. Washburn, Langmuir, 2014, 30, 9303.

39 L. Xiong, X. Qin, H. Liang, S. Huang and Z. Lian, Polym. Compos., 2017, 38, 27.

40 Y. Shan, Y. Fu and M. Qin, Adv. Mater. Res., 2012, 476-478, 2256.

41 M. Qi, K. Li, Y. Zheng, T. Rasheed and Y. Zhou, Langmuir, 2018, 34, 3058.

42 K. Ma, Y. Xu and Z. An, Macromol. Rapid Commun., 2015, 36, 566.

43 I. Capek and W. Funke, Macromol. Chem., 1990, 191, 121.

44 M. S. Cho, K. J. Yoon and B. K. Song, J. Appl. Polym. Sci., 2002, 83, 1397.

45 S. Guorong and C. Zhihai, J. Appl. Polym. Sci., 2009, 111, 1409.

46 D. Wang, PhD thesis, Zhejiang University, 2012.

47 M. Semsarilar and S. Perrier, Nat. Chem., 2010, 2, 811.

48 L. Barner, T. P. Davis, M. H. Stenzel and C. Barner-Kowollik, Macromol. Rapid Commun., 2007, 28, 539.

49 B. Voit I and A. Lederer, Chem. Rev., 2009, 109, 5924.

50 A. B. Lowe and C. L. McCormick, Prog. Polym. Sci., 2007, 32, 283.

51 X. Li, W.-J. Wang, B.-G. Li and S. Zhu, Macromol. React. Eng., 2014, 9, 90.

52 X. Li, W.-J. Wang, F. Weng, B.-G. Li and S. Zhu, Ind. Eng. Chem. Res., 2014, 53, 7321.

53 X. Li, W.-J. Wang, B.-G. Li and S. Zhu, Macromol. React. Eng., 2011, 5, 467.

54 M. Drache, G. Schmidt-Naake, M. Buback and P. Vana, Polymer, 2005, 46, 8483.

55 H. Tobita, Macromol. Theory Simul., 2009, 18, 108.

56 H. Tobita, Macromol. Theory Simul., 2009, 18, 120.

57 Y. Luo and B. Yu, Polym.-Plast. Technol. Eng., 2004, 43, 1299.

58 P. Vana, T. P. Davis and C. Barner-Kowollik, Macromol. Theory Simul., 2002, 11, 823.

59 A. Feldermann, A. A. Toy, H. Phan, M. H. Stenzel, T. P. Davis and C. Barner-Kowollik, Polymer, 2004, 45, 3997.

60 C. Barner-Kowollik, J. F. Quinn, D. R. Morsley and T. P. Davis, J. Polym. Sci., Part A: Polym. Chem., 2001, 39, 1353.

61 G. Jaramillo-Soto, M. L. Castellanos-Cárdenas, P. R. García-Morán, E. Vivaldo-Lima, G. Luna-Bárcenas and A. Penlidis, Macromol. Theory Simul., 2008, 17, 280.

62 A. R. Wang and S. Zhu, J. Polym. Sci., Part A: Polym. Chem., 2003, 41, 1553.

63 J. J. Hernández-Meza, G. Jaramillo-Soto, P. R. García-Morán, J. Palacios-Alquisira and E. Vivaldo-Lima, Macromol. React. Eng., 2009, 3, 101. 
64 J. C. Hernández-Ortiz, E. Vivaldo-Lima, M. A. Dubé and A. Penlidis, Macromol. Theory Simul., 2014, 23, 147.

65 P. López-Domínguez, J. C. Hernández-Ortiz, K. J. Barlow, E. Vivaldo-Lima and G. Moad, Macromol. React. Eng., 2014, 8, 706.

66 J. Pallares, G. Jaramillo-Soto, C. Flores-Cataño, E. VivaldoLima, L. M. F. Lona and A. J. Penlidis, J. Macromol. Sci., Part A: Pure Appl. Chem., 2006, 43, 1293.

67 X. Sun, Y. Luo, R. Wang, B. G. Li, B. Liu and S. Zhu, Macromolecules, 2007, 40, 849.

68 S. Liang, X. Li, W. J. Wang, B. G. Li and S. Zhu, Macromolecules, 2016, 49, 752.

69 W.-J. Wang, M. Kang, B. Huang and B.-G. Li, CN Pat., 109180859A, 2018.

70 M. Jesberger, L. Barner, M. H. Stenzel, E. Malmström, T. P. Davis and C. Barner-Kowollik, J. Polym. Sci., Part A: Polym. Chem., 2003, 41, 3847.

71 G. S. Misra and H. Narain, Macromol. Chem. Phys., 1968, 113, 85.

72 G. S. Misra and U. D. N. Bajpai, J. Macromol. Sci., Part A: Pure Appl. Chem., 1979, 13, 1135.

73 E. Mastan and S. Zhu, Eur. Polym. J., 2015, 68, 139.
74 Y.-N. Zhou and Z.-H. Luo, Macromol. React. Eng., 2016, 10, 516.

75 A. R. Wang and S. Zhu, Macromol. Theory Simul., 2003, 12, 196.

76 D. Achilias and C. Kiparissides, J. Appl. Polym. Sci., 1988, 35, 1303.

77 F. L. Marten and A. E. Hamielec, J. Appl. Polym. Sci., 1982, 27, 489.

78 P. Neogi, in Diffusion in Polymers, Marcel Dekker, New York, 1996. p. 143.

79 H. Suzuki and V. B. F. Mathot, Macromolecules, 1989, 22, 1380.

80 M. A. Dube, K. Rilling and A. Penlidis, J. Appl. Polym. Sci., 1991, 43, 2137.

81 Handbook of Chemistry and Physics, ed. Y. Yao, T. Xie and Y. Gao, Shanghai Scientific and Technical Publishers, Shanghai, 1985.

82 K. M. Jones, D. Bhattacharya, J. L. Brash and A. E. Hamielec, Polymer, 1986, 27, 602.

83 J. Brandrup, E. Immergut, E. Grulke, A. Abe, and D. Bloth, in Polymer Handbook, Wiley, New York, 4th edn, 1999.

84 R. F. Fedors, J. Polym. Sci., Polym. Lett. Ed., 1979, 17, 719. 